\title{
UM ESTUDO SOBRE OS FATORES ORGANIZACIONAIS QUE INFLUENCIAM A GESTÃO DE PORTFÓLIO DE PROJETOS DE TECNOLOGIA DA INFORMAÇÃO E COMUNICAÇÃO
}

\author{
*Cláudio Luís Carvalho Larieira \\ Claudio.larieira@fgv.br \\ *Alberto Luiz Albertin \\ albertin@fgv.br
}

*Fundação Getúlio Vargas - São Paulo, SP / Brasil

http://dx.doi.org/10.1590/1413-2311.0462014.52299

Recebido em 05/09/2014

Aprovado em 02/07/2015

Disponibilizado em 01/08/2015

Avaliado pelo sistema "double blind review"

Revista Eletrônica de Administração

Editor: Luís Felipe Nascimento

ISSN 1413-2311 (versão "on line")

Editada pela Escola de Administração da Universidade Federal do Rio Grande do Sul.

Periodicidade: Quadrimestral

Sistema requerido: Adobe Acrobat Reader.

\section{RESUMO}

A Tecnologia da Informação e Comunicação (TIC) permite que as organizações realizem suas operações de maneira mais eficiente, alavanquem suas estratégias de negócio e tragam assim as vantagens competitivas necessárias para o sucesso e perenidade do empreendimento. É constante nos meios acadêmicos e empresariais o questionamento sobre o valor que a TIC efetivamente traz ao negócio dados os altos investimentos necessários para sua aquisição, implementação e manutenção. Os investimentos realizados pelas organizações podem ser gerenciados sob a perspectiva de projetos. A Gestão de Portfólio de Projetos (GPP), por sua vez, tem por propósito realizar a identificação, avaliação, seleção e priorização de projetos estabelecendo assim um portfólio otimizado de projetos. A GPP foi posteriormente estendida para os projetos de TIC e foi proposta então a abordagem de Gestão de Portfólio de Projetos de TIC (GPPTIC). Além das questões meramente técnicas ou metodológicas, vários fatores organizacionais estão presentes na execução deste processo e podem influenciá-lo. Este estudo identifica os fatores organizacionais que envolvem a Gestão de Portfólio de Projetos de TIC e analisa as influências que estes fatores trazem sobre o processo citado. A pesquisa é de natureza qualitativa, de caráter exploratório, descritivo e é operacionalizada através da realização de estudos de caso múltiplos em 3 (três) bancos médios comerciais brasileiros. A principal contribuição deste estudo é a proposição de uma estrutura conceitual que representa os diversos fatores organizacionais que influenciam a Gestão de Portfólio de Projetos de TIC em uma organização. Há indícios de que os fatores organizacionais têm grande influência sobre este processo considerando as respostas obtidas nas entrevistas com os profissionais dos bancos analisados.

REAd | Porto Alegre - Edição 81 - № 2 - maio/agosto 2015 - p. 515-547 
UM ESTUDO SOBRE OS FATORES ORGANIZACIONAIS QUE INFLUENCIAM A GESTÃO DE PORTFÓLIO DE PROJETOS DE TECNOLOGIA DA INFORMAÇÃO E COMUNICAÇÃO

Palavras-chave: Tecnologia da Informação e Comunicação; Gestão de Projetos; Gestão de Portfólio de Projetos; Gestão de Portfólio de Projetos de TIC; Fatores Organizacionais.

\title{
A STUDY ABOUT ORGANIZATIONAL FACTORS THAT INFLUENCE INFORMATION AND COMMUNICATION TECHNOLOGY PROJECT PORTFOLIO MANAGEMENT
}

\begin{abstract}
Organizations may manage their operations more efficiently and leverage business strategies through Information and Communications Technologies (ICT), enabling them to add competitive advantages required for success and enterprise sustainability. Scholars and business leaders often dispute the value ICT brings to businesses because of high investment required for acquisition, implementation, and maintenance. Investments by organizations can be managed under the project perspective. The Project Portfolio Management, in turn, has the purpose carry out the identification, evaluation, selection and prioritization of projects thus establishing an optimized project portfolio. The Project Portfolio Management was later extended to the ICT projects and was then proposed to approach ICT Project Portfolio Management. Various organizational factors can influence the execution of this process, beyond inherent technical and methodological issues. This study identified organizational factors that affect ICT Project Portfolio Management and analyzed their influence on the process. The research is of an applied nature, qualitative, exploratory and descriptive, and was executed in multiple case studies through analysis of three mid-sized commercial Brazilian banks. This study' main contribution is reached through the creation of a conceptual structure that represents various organizational factors that influence ICT Project Portfolio Management. There are indications that organizational factors have great influence on this process, given the responses obtained in interviews with professionals of the banks analyzed.
\end{abstract}

Keywords: Information and Communications Technology; Project Management; Project Portfolio Management; ICT Project Portfolio Management; Organizational Factors.

\section{UN ESTUDIO SOBRE LOS FACTORES ORGANIZACIONALES QUE INFLUENCIAN LA GESTIÓN DE PORTFÓLIO DE PROYECTOS DE TECNOLOGÍA DE LA INFORMACIÓN Y COMUNICACIÓN}

\section{RESUMEN}

La Tecnología de la Información y Comunicación (TIC) permite que las organizaciones realicen sus operaciones de manera más eficiente, alavanquem sus estrategias de negocio y traigan así las ventajas competitivas necesarias para el éxito y longevidad del emprendimiento. És constante en los medios académicos y empresariales el cuestionamiento sobre el valor que la TIC efectivamente trae al negocio dados las grandes inversiones REAd | Porto Alegre - Edição 81 - N 2 - maio/agosto 2015 - p. 515-547 
necesarias para su adquisición, implementación y mantenimiento. Las inversiones realizadas por las organizaciones pueden ser gestionadas bajo la perspectiva de proyecto. La Gestión de Portafolio de Proyectos, por su parte, tiene el reto de llevar a cabo la identificación, evaluación, selección y priorización de proyectos estableciendo así una cartera óptima de proyectos. La Gestión de Portafolio de Proyectos se extendió posteriormente a proyectos de TIC y fué propuesta entonces el abordaje de Gestión de Portafolio de Proyectos de TIC. Además de las cuestiones meramente técnicas o metodológicas, varios factores organizacionales están presentes en la ejecución de este proceso y pueden influenciarlo. Este estudio identifica los factores organizacionales que estan envolucrados em la Gestión de Portfólio de Proyectos de TIC y analiza las influencias que estos factores traen sobre el proceso citado. La investigación és de naturaleza cualitativa, de carácter exploratório, descriptivo y és operacionalizada a través de la realización de estudios de caso múltiples en 3 (tres) bancos medios comerciales brasileños. La principal contribución de este estudio es la proposición de una estructura conceptual que representa los diversos factores organizacionales que influéncian la Gestión de Portfólio de Proyectos de TIC en una organización. Hay indicios de que los factores organizacionales tienen gran influencia sobre este proceso dadas las respuestas obtenidas en las entrevistas con los profesionales de los bancos analizados.

Palabras clave: Tecnología de la Información y Comunicación; Gestión de Proyectos; Gestión de Portafolio de Proyectos; Gestión de Portafolio de Proyectos de TIC; Factores Organizacionales.

\section{INTRODUÇÃO}

Recentes pesquisas apontam que as organizações brasileiras têm realizado significativos investimentos em TIC nos últimos anos. Segundo estimativa realizada pelo International Data Corporation (IDC, 2014), as organizações brasileiras pretendiam gastar US\$ 175 bilhões com TIC em 2014, sobretudo nas tecnologias de mobilidade, mídias sociais, computação em nuvem e Big Data. Especificamente em Comércio Eletrônico, a pesquisa realizada pelo GVcia da Fundação Getúlio Vargas (FGV) apontou que as organizações brasileiras investiram em 2012 o correspondente a 7,54\% de suas receitas líquidas (ALBERTIN, 2013). Estes investimentos realizados em TIC tipicamente são viabilizados através do desenvolvimento de projetos nas organizações.

Vários autores procuraram responder à necessidade de gerenciar investimentos das organizações usando para tanto a abordagem de projetos, criando o que hoje se denomina de Gestão de Portfólio de Projetos (GPP) (MEREDITH e MANTEL JR., 1985; COOPER, EDGETT e KLEINSCHIMIDT, 2001; ARCHER e GHASEMZADEH, 1999; PMI, 2013b).

A GPP pode ser definida como um processo dinâmico e integrado que tem por objetivo avaliar a viabilidade e alinhamento estratégico de vários projetos ao mesmo tempo,

REAd | Porto Alegre - Edição 81 - N 2 - maio/agosto 2015 - p. 515-547 
UM ESTUDO SOBRE OS FATORES ORGANIZACIONAIS QUE INFLUENCIAM A GESTÃO DE PORTFÓLIO DE PROJETOS DE TECNOLOGIA DA INFORMAÇÃO E COMUNICAÇÃO

em um formato de portfólio de projetos, sendo para tanto avaliados, selecionados e priorizados novos projetos enquanto outros projetos correntes podem ser acelerados, cancelados ou postergados (COOPER, EDGETT e KLEINSCHIMIDT, 2001; GHASEMZADEH e ARCHER, 2000; KERZNER, 2006).

Entenda-se como projeto um empreendimento multidisciplinar e temporário que é executado segundo um ciclo de vida previamente definido e que tem como objetivo criar algum produto, serviço, conhecimento ou resultado que seja único (PMI, 2013a). Um portfólio, por sua vez, representa uma coleção de projetos e/ou programas e outros trabalhos que são agrupados para facilitar a efetiva gestão para que sejam atingidos os objetivos estratégicos de uma organização (PMI, 2013b).

Posteriormente à GPP foi proposta uma abordagem específica para gerenciamento dos investimentos de TIC sob a perspectiva de portfólio de projetos (WEILL e OLSON, 1989; MAIZLISH, 2005; BONHAM, 2005), agora então com a denominação de Gestão de Portfólio de Projetos de TIC (GPPTIC).

Vários fatores organizacionais estão presentes na execução da GPPTIC e influenciam de maneira direta ou indireta seus resultados, tais como: (i) os recursos da organização, (ii) as informações de apoio ao processo, (iii) os conhecimentos e atitudes das pessoas envolvidas, (iv) as características da organização, (v) as características do processo em si e outros processos relacionados a ele, (vi) as questões de política que envolvem a organização, (vii) as estratégias organizacional e de TIC e seus desdobramentos e (viii) o modelo de gestão adotado. Assim, o problema explorado neste estudo pode ser traduzido na seguinte pergunta de pesquisa: "Quais são os fatores organizacionais que influenciam a GPPTIC e como estas influências são percebidas em organizações brasileiras?“.

O objetivo desta pesquisa é identificar os fatores organizacionais que envolvem a Gestão de Portfólio de Projetos de TIC e analisar as influências que estes fatores podem trazer sobre o processo citado. Uma estrutura conceitual é proposta e avaliada à luz de situações reais observadas em estudos de caso realizados em organizações brasileiras.

Pesquisa prévia conduzida pelos autores identificou que poucos trabalhos acadêmicos abordam os fatores organizacionais em GPP e GPPTIC (LARIEIRA e ALBERTIN, 2011). Assim, do ponto de vista acadêmico, pode-se observar pelos dados obtidos que pesquisas sobre o tema normalmente cobrem assuntos específicos e de maneira técnica, sem uma relação clara com as questões organizacionais. A maior parte dos trabalhos encontrada trata

REAd | Porto Alegre - Edição 81 - N 2 - maio/agosto 2015 - p. 515-547 
de fundamentos e de como se deve realizar o processo.

A principal contribuição deste estudo se refere à proposição de uma estrutura que sistematiza os diversos fatores organizacionais que podem influenciar de alguma maneira a GPPTIC em uma organização. Dado que na literatura pesquisada não foram encontradas estruturas semelhantes à proposta neste estudo, esta estrutura oferece respostas à uma lacuna de conhecimento até então pouco abordada nos trabalhos acadêmicos, bem como poderá ajudar organizações a se prepararem melhor para a implantação deste processo na gestão de suas áreas de TIC.

As seções deste estudo estão assim organizadas: (i) o Referencial Teórico descreve os fundamentos necessários para o entendimento deste estudo; (ii) a Metodologia de Pesquisa apresenta e justifica a escolha da abordagem de estudo de caso como estratégia desta pesquisa e estabelece o protocolo de pesquisa; (iii) são apresentados os estudos de caso realizados nas organizações pesquisadas e as análises comparativas entre os casos à luz da estrutura conceitual; (iv) são apresentadas as conclusões do estudo, suas contribuições em relação ao estado da questão, as limitações em termos de pesquisa e as sugestões de estudos futuros.

\section{REFERENCIAL TEÓRICO}

O termo TIC (Tecnologia da Informação e Comunicação) começou a ser utilizado pelos autores da década de 1980 para designar o conjunto dos softwares, sistemas de informação, computadores, bancos de dados, infraestrutura, redes, dispositivos eletrônicos e os recursos de telecomunicação, multimídia e automação que as organizações utilizam para obter, armazenar, tratar e disponibilizar informações que suportam a operação das organizações. Neste conjunto estão abrangidas as pessoas relacionadas para criar, manter e operar estes sistemas e equipamentos, bem como as consultorias e os serviços externos a serem adquiridos (WEILL e OLSON, 1989; HENDERSON e VENKATRAMAN, 1993; TAYLOR, 2004).

Se até a década de 90 os computadores e sistemas eram vistos nas organizações como um utility (à semelhança de outros recursos como água, luz e gás) (WEILL, 1986), atualmente a TIC tem o status de um recurso organizacional de extrema importância dada a capacidade que possui de gerar e manter vantagens competitivas (MCFARLAN, MCKENNEY e PYBURN, 1983; HENDERSON e VENKATRAMAN, 1993).

REAd | Porto Alegre - Edição 81 - Nº 2 - maio/agosto 2015 - p. 515-547 
UM ESTUDO SOBRE OS FATORES ORGANIZACIONAIS QUE INFLUENCIAM A GESTÃO DE PORTFÓLIO DE PROJETOS DE TECNOLOGIA DA INFORMAÇÃO E COMUNICAÇÃO

Um projeto pode ser considerado uma atividade multidisciplinar na medida em que vários temas são abrangidos quando de sua execução, bem como temporário porque ele possui datas de inicio e fim determinados (MARTIN, 1976; PMI, 2013a), além de possuir a caraterística ser multirecurso devido ao fato de envolver tanto recursos humanos quanto financeiros e materiais (KERZNER, 2006; PMI, 2013a; DINSMORE e CABANIS-BREWIN, 2009).

A gestão de projetos é um processo disciplinado e tem por propósito geral garantir que os objetivos definidos para um projeto sejam plenamente atingidos, respeitando os custos, o prazo e o desempenho requerido e isto se realiza através do envolvimento de pessoas em atividades de organização, planejamento e controle das atividades e dos recursos alocados ao projeto (MARTIN, 1976; MEREDITH e MANTEL JR., 1985; KERZNER, 2006; DINSMORE e CABANIS-BREWIN, 2009). Para tanto, são empregados conhecimentos, habilidades, técnicas e ferramentas (PMI, 2013a).

Dado que um projeto de TIC é antes de tudo um tipo de projeto, pode-se afirmar que os projetos de TIC conservam todas as características para um projeto como outro qualquer (ou seja, possui inicio e fim, é multidisciplinar, tem entregáveis específicos, sofre restrições de custo e tempo, etc.) (TAYLOR, 2004; DINSMORE e CABANIS-BREWIN, 2009). O que de fato diferencia um projeto de TIC dos demais tipos de projeto são os produtos por ele entregues e as características do processo de construção deste produto. Se em outros tipos de projeto podem ser entregues viadutos, pontes, produtos, equipamentos, processos, conhecimentos, etc., nos projetos de TIC são entregues implementações dos vários recursos ou componentes de TIC à organização (MCFARLAN, MCKENNEY e PYBURN, 1983; TAYLOR, 2004).

Segundo Meredith e Mantel Jr. (1985), a avaliação e seleção de projetos é o processo de avaliar projetos individuais ou grupos de projetos e então escolher destes quais serão implementados de forma que os objetivos estratégicos da organização sejam atingidos.

Archer e Ghasemzadeh (1999) propuseram um modelo para a seleção de projetos que consiste de 6 (seis) estágios discretos e inter-relacionados: (i) do Desenvolvimento Estratégico, que consiste da determinação do foco e diretrizes estratégicas pelos líderes da organização, da definição das limitações de recursos e da escolha das técnicas de seleção de projetos a serem empregadas; (ii) da Pré-triagem dos projetos propostos para identificar se estão alinhados com as diretrizes estratégicas estabelecidas pela organização; (iii) da Análise

REAd | Porto Alegre - Edição 81 - N 2 - maio/agosto 2015 - p. 515-547 
individual dos projetos para verificar a aderência ao foco e estratégia da organização; (iv) da Triagem para determinar quais projetos podem ser eliminados por não atenderem a critérios mínimos exigidos pelos comitês de seleção; (v) da Seleção do portfólio ótimo, quando os projetos são submetidos a um comitê de seleção de projetos que analisa a contribuição de cada projeto ao portfólio e determina quais serão os projetos selecionados; (vi) do Ajuste do portfólio para realizar o balanceamento final do portfólio através da incorporação ou exclusão de projetos ao portfólio.

Enquanto a seleção de projetos tem por objetivo avaliar um projeto individualmente e determinar se este projeto representa um bom investimento para uma organização, a Gestão de Portfólio de Projetos (GPP) pode ser definida como um processo em que projetos são submetidos a um "funil" que tem como principal objetivo escolher somente os "melhores projetos" para a composição de um portfólio (COOPER, EDGETT e KLEINSCHMIDT, 2001).

Desta forma, a GPP pode ser vista como uma evolução natural da atividade de seleção de projetos e representa um processo mais holístico e integrado (considerando conhecimentos, perfis, ferramentas e técnicas), sendo composto por vários estágios de decisão, tendo como objetivo criar e gerenciar de maneira centralizada portfólios de projetos alinhados às diretrizes estratégicas estabelecidas por uma organização à luz de suas restrições financeiras, de tecnologia, de tempo e de recursos humanos (GHASEMZADEH e ARCHER, 2000; PENNYPACKER, 2005; PMI, 2013b).

Os componentes de um portfólio devem ser quantificáveis, ou seja, devem possuir atributos que permitam aos gestores de um portfólio de projetos mensurá-los, classificá-los e priorizá-los sempre que necessário. Não é obrigatório que os componentes do portfólio (ou projetos) sejam interdependentes ou diretamente relacionados, mas é importante que um portfólio reflita uma visão de investimentos em um dado momento (PMI, 2013b).

Várias evoluções foram propostas pelos autores à GPP e atualmente este processo pode ser composto das seguintes atividades (MEREDITH e MANTEL JR., 1985; ENGLUND e GRAHAM, 1999; COOPER, EDGETT e KLEINSCHIMIDT, 2001; PENNYPACKER, 2005; KERZNER, 2006; PMI, 2013b): (i) Estabelecimento de Estrutura organizacional; (ii) Identificação de potenciais projetos; (iii) Categorização de projetos; (iv) Criação de critérios de avaliação dos projetos; (v) Avaliação dos projetos; (vi) Levantamento de capacidade e recursos de organização; (vii) Seleção dos projetos; (viii) Priorização dos projetos; (ix) 
UM ESTUDO SOBRE OS FATORES ORGANIZACIONAIS QUE INFLUENCIAM A GESTÃO DE PORTFÓLIO DE PROJETOS DE TECNOLOGIA DA INFORMAÇÃO E COMUNICAÇÃO

Balanceamento do portfólio de projetos; (x) Autorização dos projetos; (xi) Monitoramento e controle; (xii) Reporte e revisão; (xiii) Replanejamento ou Mudança Estratégica.

A Gestão de Portfólio de Projetos de TIC (GPPTIC) é uma derivação da GPP e engloba específica e tão somente os projetos de TIC (JEFFERY e LELIVELD, 2004). A oportunidade que as organizações encontram ao adotar a GPPTIC é a de combinar em uma mesma abordagem os benefícios da gestão de portfólio (com uma perspectiva financeira) e da gestão de projetos de TIC (BONHAM, 2005).

Para a identificação dos fatores organizacionais que influenciam a GPPTIC foram consultados trabalhos acadêmicos que citam de maneira direta ou indireta estes fatores. Tendo como objetivo aumentar a probabilidade de se encontrar tais fatores, foi assumida a premissa de que os fatores organizacionais que influenciam a GPP podem ser generalizáveis à GPPTIC.

A partir da identificação e definição dos fatores organizacionais citados na literatura foi realizado um trabalho de agrupamento destes fatores, conforme as afinidades observadas entre eles, sendo gerada então a estrutura reperesentada pela figura 1 abaixo. Nesta estrutura, a variável caracterizada como dependente é a variável Sucesso da GPPTIC, que consequentemente é influenciada pelas variáveis independentes caracterizadas pelos fatores organizacionais que compõem os agrupamentos acima descritos. 


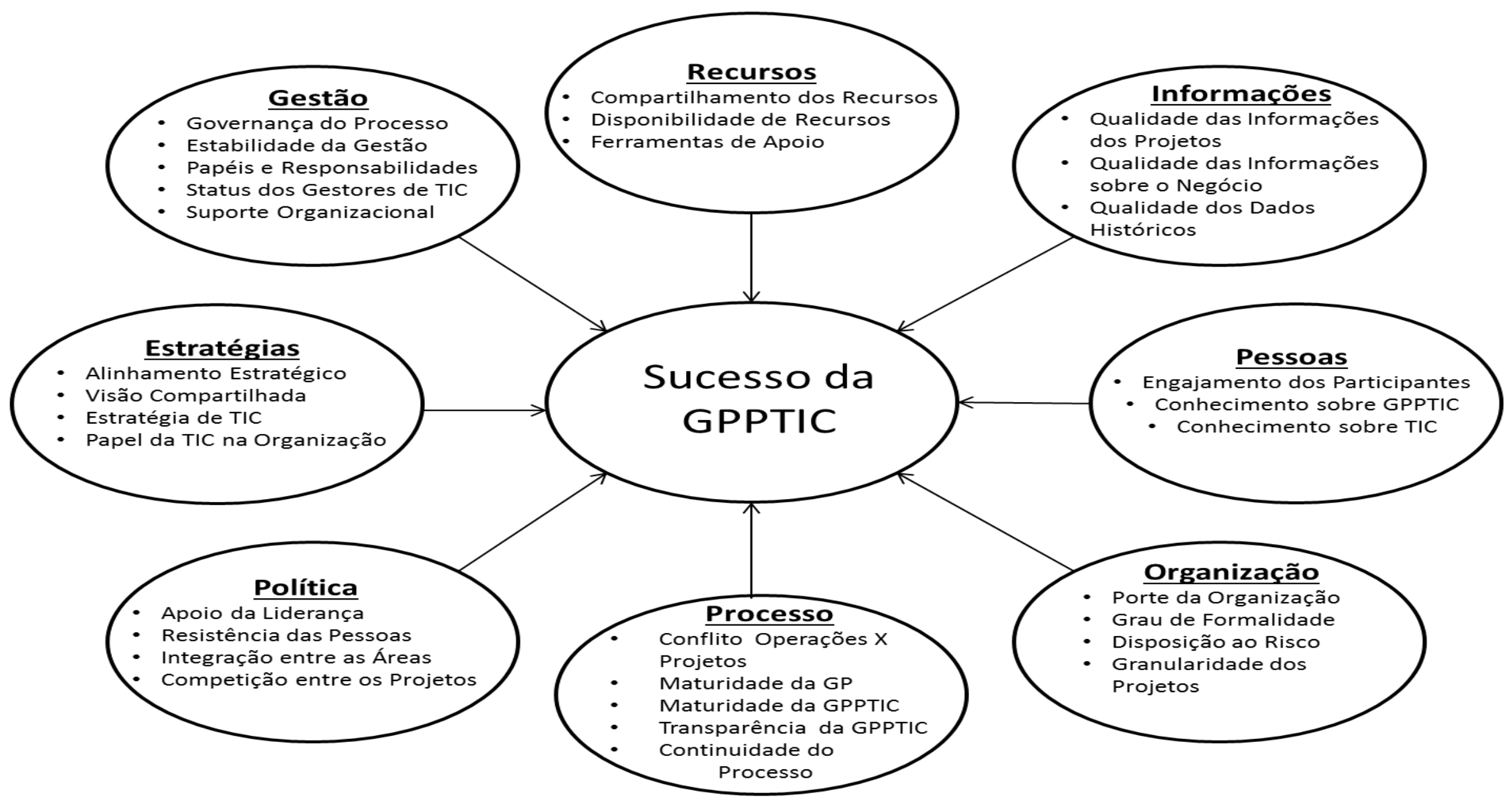

Figura 1 - Fatores Organizacionais que influenciam a GPPTIC

Fonte: Autores

REAd | Porto Alegre - Edição 81 - N 2 - maio/agosto 2015 - p. 515-547 
Os recursos da organização podem influenciar a GPPTIC através de 3 (três) fatores: (i) Compartilhamento dos Recursos - Tipicamente os recursos de uma organização são compartilados entre vários projetos ao mesmo tempo, estabelecendo um formato matricial de uso dos recursos (COOPER, EDGETT e KLEINSCHIMIDT, 2001; ENGWALL e JERBRANT, 2003; DOOLEY, LUPTON e O'SULLIVAN, 2005; PENNYPACKER, 2005);

(ii) Disponibilidade de Recursos - É importante efetuar um levantamento prévio e minucioso para identificar os recursos necessários para o desenvolvimento dos projetos e avaliar a necessidade de contratação de recursos adicionais (ENGLUND e GRAHAM, 1999; DOOLEY, LUPTON e O’SULlIVAN, 2005); (iii) Ferramentas de Apoio - Sistemas devem suportar este processo para garantir o tratamento e o registro adequado das informações dos projetos e dos resultados do processo (ENGLUND e GRAHAM, 1999).

A qualidade das informações que serão utilizadas no processo pode ser afetada por 3 (três) fatores: (i) Qualidade das Informações dos Projetos - As informações dos projetos que estão sendo avaliados é um fator amplamente citado pelos autores quando alertam sobre a necessidade de se verificar a qualidade dos dados obtidos bem como a eficiência das técnicas de coleta de dados (COOPER, EDGETT e KLEINSCHIMIDT, 2001; DOOLEY, LUPTON e O'SULLIVAN, 2005; PENNYPACKER, 2005; MOECKEL e FORCELINNI, 2009; KAISER, ARBI e AHLEMANN, 2014); (ii) Qualidade das Informações sobre o Negócio Os gestores tem dificuldade em avaliar os projetos e isto ocorre em grande parte por conta da qualidade ruim das informações sobre o negócio (COOPER, EDGETT e KLEINSCHIMIDT, 2001; MOECKEL e FORCELINNI, 2009; KAISER, ARBI e AHLEMANN, 2014); (iii) Qualidade dos Dados Históricos - Além de informações sobre os projetos em análise e do negócio, é necessário que se tenha uma base de dados contendo as informações dos projetos passados; isto viabilizará estimativas e simulações confiáveis para definir prazos e recursos para os novos projetos (ENGLUND e GRAHAM, 1999; JEFFERY e LELIVELD, 2004; MOECKEL e FORCELINNI, 2009).

Em relação às pessoas, foram encontrados 3 (três) fatores organizacionais: (i) Engajamento dos Participantes - Por vezes faz-se necessário "evangelizar" as áreas da organização e seus gestores sobre a importância e benefícios da GPP, tendo como finalidade obter o máximo de engajamento deles no processo (ENGLUND e GRAHAM, 1999; JAYME, PERRONE, MONTEIRO, TORRES e EICHMANN, 2006); um estudo quantitativo realizado com empresas de desenvolvimento de software no Paquistão demonstrou que o engajamento dos Stakeholders internos tem efeito signifcativo sobre o sucesso da GPPTIC (SHAH e REAd | Porto Alegre - Edição 81 - N 2 - maio/agosto 2015 - p. 515-547 
Cláudio Luís Carvalho Larieira \& Alberto Luiz Albertin

NAQVI, 2014); (ii) Conhecimento sobre GPPTIC - Os profissionais envolvidos na GPPTIC devem possuir conhecimento básico sobre as atividades e as técnicas a serem empregadas neste processo (JEFFERY e LELIVELD, 2004; JAYME, PERRONE, MONTEIRO, TORRES e EICHMANN, 2006); (iii) Conhecimento sobre TIC - O conhecimento dos gestores das áreas de negócio sobre a TIC e os benefícios que ela entrega ao negócio é um fator que potencialmente influencia a GPPTIC (JEFFERY e LELIVELD, 2004);.

As caraterísticas da organização podem influenciar a GPPTIC através dos seguintes fatores: (i) Porte da Organização - Quanto maior o tamanho e a complexidade de uma organização, maior será a necessidade de processos e sistemas de informação para a execução do processo de GPPTIC (MCFARLAN, MCKENNEY e PYBURN, 1983); (ii) Grau de Formalidade - Organizações podem adotar estilos de comunicação mais formais ou menos formais quando gerenciam seus negócios e projetos, o que implicitamente se transfere ao processo de GPPTIC (MCFARLAN, MCKENNEY e PYBURN, 1983; DOOLEY, LUPTON e O’SUlliVAN, 2005); (iii) Disposição ao Risco - Quando uma organização seleciona projetos é natural que durante este processo venha à tona a sua disposição em tomar mais riscos ou menos riscos (CHRISTIANSEN e VARNES, 2008); Teller, Kock e Gemumdem (2104) em recente trabalho discutiram a necessidade de se gerenciar riscos no nível do portfólio ao invés de apenas gerenciar riscos no nível dos projetos e demonstraram de maneira quantitativa que há melhoras no sucesso do portfólio do projetos quando estas práticas são executadas de maneira conjunta; (iv) Granularidade dos Projetos - Uma organização pode ter em seu portfólio projetos com tamanhos diferentes, o que pode dificultar a execução da GPP por conta do esforço necessário para avaliá-los, selecioná-los e priorizá-los (COOPER, EDGETT e KLEINSCHIMIDT, 2001).

As características inerentes ao processo de GPPTIC bem como a outros processos aos quais ele se relaciona de alguma maneira podem ser influenciados por: (i) Conflito Operações X Projetos - Há organizações que, sem perceber, estão mais focadas em resolver problemas de curto prazo da operação do que darem prioridade às ações de longo prazo, tendo como consequência a perda de foco do portfólio de projetos (ENGWALL e JERBRANT, 2003; DOOLEY, LUPTON e O'SULLIVAN, 2005; CHRISTIANSEN e VARNES, 2008); (ii) Maturidade da GP - Executar o processo de GPP implica em que uma organização possua previamente institucionalizados os processos de gestão de projetos, sob pena de não haver informações em quantidade e qualidade suficientes sobre os projetos e seus resultados para alimentar a GPP (DOOLEY, LUPTON e O'SULLIVAN, 2005; PENNYPACKER, REAd | Porto Alegre - Edição 81 - N 2 - maio/agosto 2015 - p. 515-547 
UM ESTUDO SOBRE OS FATORES ORGANIZACIONAIS QUE INFLUENCIAM A GESTÃO DE PORTFÓLIO DE PROJETOS DE TECNOLOGIA DA INFORMAÇÃO E COMUNICAÇÃO

2005) (GUEDES et al, 2011); (iii) Maturidade da GPTTIC - Algumas organizações executam a GPPTIC, porém sem uma formalização do processo, o que pode gerar entendimentos ambíguos dos participantes (JEFFERY e LELIVELD, 2004; PENNYPACKER, 2005; JAYME, PERRONE, MONTEIRO, TORRES e EICHMANN, 2006; MORAES e GARCEZ, 2014); (iv) Transparência da GPPTIC - Um processo como este requer comunicação constante, o que evita ou diminui a resistência das pessoas ao processo bem como aumenta o nível de engajamento no processo; o nível de transparência que se atribui ao processo se traduz no quanto a organização explicita ou não sobre as politicas, os critérios de decisão empregados e os resultados da GPP (DOOLEY, LUPTON e O'SUllivan, 2005; PENNYPACKER, 2005); (v) Continuidade do Processo - De maneira geral, as organizações executam seus processos de GPP em períodos determinados do ano; como o processo de GPPTIC é um processo cíclico e dinâmico, sua continuidade no tempo pode se configurar como um fator organizacional (DOOLEY, LUPTON e O'SULLIVAN, 2005).

As questões que envolvem política entre os participantes e as áreas da organização são constituídas dos seguintes fatores: (i) Apoio da Liderança - É imprescindível que os líderes apoiem o processo na organização para que este não venha a sofrer boicotes pelos gerentes táticos e operacionais durante sua execução e acompanhamento (DOOLEY, LUPTON e O'SULLIVAN, 2005; JAYME, PERRONE, MONTEIRO, TORRES e EICHMANN, 2006); (ii) Resistência das Pessoas - Por se tratar de um processo que envolve decisões sobre investimentos em projetos, a GPPTIC possui um viés altamente politico, o que pode causar certas resistências das pessoas envolvidas em algum momento (ENGLUND e GRAHAM, 1999); (iii) Integração entre as Áreas - Não é incomum que nas organizações uma ou várias áreas façam a seleção e priorização de projetos de TIC sem considerar que estes projetos podem também estar na pauta de outras áreas (JEFFERY e LELIVELD, 2004; DOOLEY, LUPTON e O'SUlliVAN, 2005); (iv) Competição entre os Projetos - A competição entre os projetos pode estar presente em uma organização de maneira deliberada ou implícita, o que potencializa o problema da "Síndrome de Alocação de Recursos" (ENGWALL e JERBRANT, 2003; DOOLEY, LUPTON e O'SULLIVAN, 2005).

As estratégias da organização tem relação direta com a GPPTIC através dos seguintes fatores: (i) Alinhamento Estratégico - As organizações tipicamente definem sua visão, 
Cláudio Luís Carvalho Larieira \& Alberto Luiz Albertin

missão, crenças, valores e objetivos estratégicos e estas informações servem de insumo para avaliação e seleção dos projetos de TIC (JEFFERY e LELIVELD, 2004; DOOLEY, LUPTON e O'SULLIVAN, 2005; PENNYPACKER, 2005; JAYME, PERRONE, MONTEIRO, TORRES e EICHMANN, 2006; KAISER, ARBI e AHLEMANN, 2014); (ii) Visão Compartilhada - O estabelecimento de comitês de seleção de projetos e a participação de membros da alta gestão são importantes fatores críticos de sucesso para a adoção de GPPTIC, pois garante que a alta gestão e os gerentes de projeto compartilhem de uma mesma visão em termos de estratégia e projetos (ENGLUND e GRAHAM, 1999; JEFFERY e LELIVELD, 2004; PENNYPACKER, 2005); (iii) Estratégia de TIC - O desenvolvimento de uma estratégia de TIC alinhada às diretrizes estratégicas da organização facilita a execução da GPPTIC, já que serve de insumo e parâmetro para este processo (JEFFERY e LELIVELD, 2004) (iv) Papel da TIC na Organização - A TIC pode ser utilizada pelas organizações das mais diversas maneiras, assumindo em alguns casos um papel altamente estratégico para a viabilização do negócio e em outros casos servindo apenas como um suporte ao negócio (MCFARLAN, MCKENNEY e PYBURN, 1983).

Por fim, o modelo de gestão adotado pela organização pode trazer influências ao processo de GPPTIC por conta de: (i) Governança do Processo - Para que a GPP tenha sucesso em uma organização, faz-se necessário estabelecer uma governança de maneira que sejam claras e entendidas por todos os participantes as regras de como o processo será executado (PENNYPACKER, 2005; CHRISTIANSEN e VARNES, 2008); (ii) Estabilidade da Gestão - A estabilidade do ambiente organizacional em relação à gestão também pode influenciar o planejamento dos sistemas de informações (MCFARLAN, MCKENNEY e PYBURN, 1983); (iii) Papéis e Responsabilidades - O estabelecimento de Papéis e Responsabilidades para o processo de GPP ajudará com que o processo seja executado com sucesso (PENNYPACKER, 2005); (iv) Status dos Gestores de TIC - A proximidade dos gestores de TIC em relação à alta liderança da organização pode melhorar a comunicação e portanto facilitar o entendimento sobre como a TIC deve atender às necessidades e demandas do negócio (MCFARLAN, MCKENNEY e PYBURN, 1983); (v) Suporte Organizacional Para que a GPP seja implementada com sucesso em uma organização é recomendado que uma unidade organizacional ou uma área seja criada com o objetivo de executar ou dar suporte a este processo (ENGLUND e GRAHAM, 1999; JEFFERY e LELIVELD, 2004; JAYME, PERRONE, MONTEIRO, TORRES e EICHMANN, 2006), bem como o estabelecimento de processos e sistemas para criar, processar e disponibilizar informações necessárias à GPP REAd | Porto Alegre - Edição 81 - Nº 2 - maio/agosto 2015 - p. 515-547 
UM ESTUDO SOBRE OS FATORES ORGANIZACIONAIS QUE INFLUENCIAM A GESTÃO DE PORTFÓLIO DE PROJETOS DE TECNOLOGIA DA INFORMAÇÃO E COMUNICAÇÃO

(KAISER, ARBI e AHLEMANN, 2014).

\section{METODOLOGIA}

Para viabilizar esta pesquisa foi adotada a estratégia de estudos de caso múltiplos. Segundo Yin (2010), um estudo de caso é uma forma de investigação empírica que investiga um fenômeno contemporâneo em profundidade e seu contexto de vida real, especialmente quando os limites entre o fenômeno e o contexto não são claramente evidentes. A utilização de estudos de caso como método de pesquisa neste estudo se relaciona com a necessidade de se entender "como" (BENBASAT, GODLSTEIN e MEAD, 1987; YIN, 2010) os fatores organizacionais influenciam o processo de GPPTIC nas organizações, não sendo necessário o controle do pesquisador sobre os eventos reais e contemporâneos nas organizações-escopo deste estudo.

Este estudo possui um caráter exploratório e descritivo (YIN, 2010). Neste sentido, não há a expectativa de se predizer fatos nem de se testar proposições ou relações causais. Dada a necessidade de se obter o maior número possível de fatores para a composição da estrutura proposta, são utilizados projetos de casos múltiplos com uma abordagem holística em que as unidades de análise são únicas dentro de seus contextos (YIN, 2010). Esta estratégia de pesquisa permite que se tenha um estudo mais robusto já que os resultados obtidos são mais "generalizáveis" em termos de evidências.

Foi utilizada como estratégia de seleção de casos a amostragem criteriosa (DUBÉ e PARÉ, 2003), estratégia esta que estabelece que os casos selecionados possuam certas características pré-determinadas. Foram selecionados 3 (três) bancos brasileiros de varejo de porte médio para a comparação e validação da teoria (BENBASAT, GODLSTEIN e MEAD, 1987), o que permite realizar a replicação literal entre os casos (DUBÉ e PARÉ, 2003; YIN, 2010). A maior parte dos bancos brasileiros atualmente utiliza a TIC para realizar suas operações e gerar vantagem competitiva e estratégica (WEILL e OLSON, 1989), dai a relevância de se usar casos de um segmento como este.

Um primeiro conjunto de critérios definido para a seleção dos bancos diz respeito ao tipo de organização que deveria ser selecionada para garantir uma adequada representatividade sobre o uso de TIC. Os bancos selecionados: (i) desenvolvem projetos de REAd | Porto Alegre - Edição 81 - N 2 - maio/agosto 2015 - p. 515-547 
Cláudio Luís Carvalho Larieira \& Alberto Luiz Albertin

TIC que abrangem diferentes tipos de implementação; (ii) possuem relativa experiência e maturidade no uso da TIC; (iii) tem pelo menos 50 (cinquenta) profissionais atuando diretamente na área de TIC; (iv) possuem orçamentos anuais de TIC superiores a R\$ 10.000.000,00 (dez milhões de reais). Um segundo conjunto de critérios dizia respeito também ao tipo de organização, porém agora com relação ao uso das boas práticas de gestão de projetos e de gestão de portfólio de projetos: (i) executam boas práticas de gestão de projetos nos últimos 3 (três) anos em suas áreas de TIC; (ii) executam boas práticas de gestão de portfólio de projetos nos últimos 2 (dois) anos em suas áreas de TIC; (iii) desenvolvem de maneira concorrente pelo menos 40 (quarenta) projetos de TIC.

Em termos de fontes de dados (BENBASAT, GODLSTEIN e MEAD, 1987; EISENHARDT, 1989; YIN, 2010) foram coletados documentos, realizadas entrevistas com gestores das organizações e aplicados questionários. Foram também usados dados secundários nas situações em que o dado primário não era suficiente para se entender as organizações.

As informações nos bancos foram coletadas em 3 (três) momentos distintos: (i) uma reunião de uma hora, em média, com algum executivo da organização com o objetivo de colher dados sobre a organização; (ii) uma reunião de uma hora, em média, com o executivo responsável pelo processo de GPPTIC na organização com o objetivo de obter informações mais específicas sobre o processo; (iii) a aplicação de questionários sobre os fatores organizacionais, sendo dividida em reuniões separadas (demandantes de projetos, executores de projetos e tomadores de decisão); cada reunião levou de 40 minutos à uma hora em média e teve a participação de 2 (dois) a 3 (três) respondentes em cada um destes grupos.

Conforme recomenda Yin (2010), foi elaborado um protocolo de pesquisa e criados 4 (quatro) instrumentos para suportar a coleta de dados: (i) E-mail de Apresentação aos responsáveis dos bancos; (ii) Questionário sobre o Banco - roteiro semiestruturado, criado para a entrevista com o responsável pelo estudo de caso; (iii) Questionário sobre o Processo GPPTIC - roteiro semiestruturado, criado para a entrevista com o responsável pelo processo de GPPTIC; (iv) Questionário sobre os Fatores Organizacionais em GPPTIC - questionário estruturado com questões fechadas em formato de escala Likert com 5 pontos, criado para realizar as entrevistas com os demandantes, executores e decisores dos projetos de TIC.

A coleta de dados ocorreu entre os meses de Setembro de 2012 a Agosto de 2013. Os profissionais entrevistados tiveram seus nomes preservados nos relatórios dos estudos de casos e codinomes foram estabelecidos a eles para garantir a privacidade e confidencialidade 
UM ESTUDO SOBRE OS FATORES ORGANIZACIONAIS QUE INFLUENCIAM A GESTÃO DE PORTFÓLIO DE PROJETOS DE TECNOLOGIA DA INFORMAÇÃO E COMUNICAÇÃO

dos participantes da pesquisa (YIN, 2010). Conforme recomendado por Eisenhardt (1989), logo após a pesquisa de campo para cada estudo de caso realizado foi feita a transcrição das entrevistas e foram compilados em planilhas os dados dos questionários com as respectivas descrições e evidências obtidas sobre os fatores organizacionais.

A partir dos dados coletados através das documentações, entrevistas e questionários, foi possível comparar as informações entre si, o que se configurou como uma triangulação (YIN, 2010). A triangulação ajudou na verificação dos elementos da estrutura conceitual uma vez que contava com evidências de múltiplas fontes (EISENHARDT, 1989). Para realizar a análise das informações coletadas nas entrevistas sobre as organizações e seus respectivos processos de GPPTIC foi utilizada a técnica de análise de conteúdo, conforme proposto por Bardin (2004). Com relação aos questionários, através da compilação e análise dos dados foram identificadas as influências que cada fator organizacional produz sobre o processo de GPPTIC. Os dados coletados sobre as influências dos fatores organizacionais permitiu que se fizessem análises sob 2 (dois) aspectos: (i) a influência dos fatores organizacionais em cada banco estudado; (ii) a influência dos fatores organizacionais entre os 3 (três) cenários de estudo de caso, de maneira comparativa e tendo como objetivo confirmar a replicação literal.

Posteriormente à apresentação de cada estudo de caso foi elaborada uma análise conjunta dos resultados entre os casos (cross-case) tendo como objetivo apresentar os pontos em comum (EISENHARDT, 1989). Foi avaliada a extensão da lógica da replicação presente nestes estudos através de Síntese Cruzada dos Casos (YIN, 2010).

\section{ESTUDOS DE CASO}

Esta seção apresenta os estudos de caso realizados para o desenvolvimento deste trabalho de pesquisa. Foram realizados levantamentos em 3 (três) bancos brasileiros que a partir de então serão denominados apenas como Banco X, Banco Y e Banco Z.

O Banco X opera no segmento comercial de varejo, é de capital aberto e é considerado um banco de médio porte. Originalmente, era uma empresa da área de empréstimos pessoais e de CDC (Crédito Direto ao Consumidor) para as classes sociais C e D e foi fundada por um grupo de organizações de uma importante família do ramo de entretenimento no Brasil. O REAd | Porto Alegre - Edição 81 - N 2 - maio/agosto 2015 - p. 515-547 
Cláudio Luís Carvalho Larieira \& Alberto Luiz Albertin

Banco X operou neste formato durante pouco mais de 20 (vinte) anos até, que em meados de 2010, foi adquirido por outro banco do mesmo segmento. Atualmente o Banco X opera nos segmentos de financiamento de veículos, empréstimos pessoais, consignados, cartões de crédito, seguradora, corretora de valores e consórcio. Segundo o executivo entrevistado, “o banco também já não se apresenta como um banco segmentado por classe social, pelo contrário, têm na sua carteira de clientes hoje pessoas de todas as classes sociais”.

O Banco Y opera como banco múltiplo, possui capital aberto, é considerado um banco de médio porte e atende apenas a organizações de pequeno e médio porte que são clientes de outras organizações do grupo empresarial ao qual pertence. O Banco Y possui pouco mais de 25 (vinte e cinco) anos de existência e foi criado a partir de uma das maiores organizações de distribuição e logística do Brasil. Além de banco comercial, o Banco Y em seu braço financeiro possui uma corretora de valores, uma empresa de seguros e uma empresa de processamento de cartões de crédito. A empresa de seguros oferece seguros para pessoa física e jurídica, principalmente nos ramos Vida, Capitalização, Automóveis e Proteção ao Negócio. No segmento de cartões, a empresa opera no segmento de Private Label (cartões com bandeira própria) e possui uma rede própria de captura de transações de débito e de crédito.

O Banco Z foi criado na década de 1980 a partir de um grande conglomerado têxtil instalado no Brasil e definiu como sua vocação desde então oferecer crédito às organizações do segmento de mercado conhecido como Middle-Market (segmento de organizações que faturam entre R \$ 30 milhões a R \$ 400 milhões ao ano). Neste segmento, o Banco Z atende organizações de vários tipos (comercial, serviços, indústria, agronegócio, etc.) e se intitula como um banco múltiplo dado que, além dos produtos de crédito, oferece outros produtos bancários tradicionais como câmbio, derivativos, financiamento, cartões, etc.

O quadro abaixo apresenta de forma sintética as características dos Bancos X, Y e Z.

Quadro 1 - Informações complementares dos Bancos X, Y e Z

CARACTERISTICAS
\begin{tabular}{|l|l|l|l|}
\hline Origem do banco & $\begin{array}{l}\text { Fundado a partir de um } \\
\text { conglomerado de empresas } \\
\text { do segmento de } \\
\text { entretenimento }\end{array}$ & $\begin{array}{l}\text { Fundado a partir de um } \\
\text { conglomerado de empresas do } \\
\text { segmento de distribuição e } \\
\text { logística }\end{array}$ & $\begin{array}{l}\text { Fundado a partir de um } \\
\text { conglomerado de empresas do } \\
\text { segmento têxtil }\end{array}$ \\
\hline Fundação & Fim da década de 80 & Fim da década de 80 & Começo da década de 80 \\
\hline Controle acionário & Empresa de capital aberto, & Empresa de capital aberto, & Empresa de capital aberto, \\
\hline
\end{tabular}

REAd | Porto Alegre - Edição 81 - N 2 - maio/agosto 2015 - p. 515-547 
UM ESTUDO SOBRE OS FATORES ORGANIZACIONAIS QUE INFLUENCIAM A GESTÃO DE PORTFÓLIO DE PROJETOS DE TECNOLOGIA DA INFORMAÇÃO E COMUNICAÇÃO

\begin{tabular}{|c|c|c|c|}
\hline & $\begin{array}{l}\text { mas controle acionário } \\
\text { realizado por grupo familiar }\end{array}$ & $\begin{array}{l}\text { mas controle acionário } \\
\text { realizado por grupo familiar }\end{array}$ & $\begin{array}{l}\text { mas controle acionário } \\
\text { realizado por grupo familiar }\end{array}$ \\
\hline Porte da organização & Médio & Médio & Médio \\
\hline Tipo de banco & Comercial de varejo & Múltiplo & Múltiplo \\
\hline $\begin{array}{l}\text { Segmentação de } \\
\text { clientes }\end{array}$ & Pessoas Físicas & $\begin{array}{l}\text { Pessoas Jurídicas de pequeno } \\
\text { e médio porte }\end{array}$ & $\begin{array}{l}\text { Pessoas Jurídicas de médio e } \\
\text { grande porte }\end{array}$ \\
\hline Produtos e serviços & $\begin{array}{l}\text { Financiamento de veículos, } \\
\text { empréstimos, consignados, } \\
\text { cartões de crédito, } \\
\text { seguradora, corretora de } \\
\text { valores e consórcio }\end{array}$ & $\begin{array}{l}\text { Empréstimos, corretagem de } \\
\text { valores, seguros e cartões de } \\
\text { crédito }\end{array}$ & $\begin{array}{l}\text { Crédito, câmbio, derivativos, } \\
\text { financiamento, cartões de } \\
\text { crédito }\end{array}$ \\
\hline Presença física & $\begin{array}{l}\text { Não possui agências } \\
\text { bancárias, realiza } \\
\text { relacionamentos e operações } \\
\text { através de escritórios de } \\
\text { representação }\end{array}$ & $\begin{array}{l}\text { Não possui agências } \\
\text { bancárias, realiza } \\
\text { relacionamentos e operações } \\
\text { através de escritórios de } \\
\text { representação }\end{array}$ & $\begin{array}{l}\text { Não possui agências } \\
\text { bancárias, realiza } \\
\text { relacionamentos e operações } \\
\text { através de escritórios de } \\
\text { representação }\end{array}$ \\
\hline Modelo de gestão & $\begin{array}{l}\text { Gestão e operação em } \\
\text { processo de } \\
\text { profissionalização, mas } \\
\text { possui presença de membros } \\
\text { da família através de cargos } \\
\text { de liderança ou de } \\
\text { participação no Conselho }\end{array}$ & $\begin{array}{l}\text { Gestão e operação em } \\
\text { processo de } \\
\text { profissionalização, mas possui } \\
\text { presença de membros da } \\
\text { família através de cargos de } \\
\text { liderança ou de participação } \\
\text { no Conselho }\end{array}$ & $\begin{array}{l}\text { Gestão e operação em } \\
\text { processo de } \\
\text { profissionalização, mas possui } \\
\text { presença de membros da } \\
\text { família através de cargos de } \\
\text { liderança ou de participação } \\
\text { no Conselho }\end{array}$ \\
\hline Estilo de gestão & Conservador & Conservador & Conservador \\
\hline $\begin{array}{l}\text { Número de } \\
\text { funcionários (banco) }\end{array}$ & $\begin{array}{l}\text { Aproximadamente } 900 \\
\text { (novecentos) colaboradores }\end{array}$ & $\begin{array}{l}\text { Aproximadamente } 900 \\
\text { (novecentos) colaboradores }\end{array}$ & $\begin{array}{l}\text { Aproximadamente } 3.000 \text { (três } \\
\text { mil) colaboradores }\end{array}$ \\
\hline $\begin{array}{l}\text { Número de } \\
\text { funcionários (em TI) }\end{array}$ & $\begin{array}{l}\text { Possui por volta de } 100 \\
\text { (cem) profissionais, mas } \\
\text { contrata desenvolvimento e } \\
\text { manutenção de sistemas de } \\
\text { parceiros externos }\end{array}$ & $\begin{array}{l}\text { Possui por volta de } 120 \text { (cento } \\
\text { e vinte) profissionais, em sua } \\
\text { maioria recursos internos da } \\
\text { empresa }\end{array}$ & $\begin{array}{l}\text { Possui por volta de } 80 \\
\text { (oitenta) profissionais, em sua } \\
\text { maioria recursos internos da } \\
\text { empresa }\end{array}$ \\
\hline Resultado em 2012 & Prejuízo de $\mathrm{R} \$ 604$ milhões & $\begin{array}{l}\text { Lucro líquido de } \mathrm{R} \$ 25,67 \\
\text { milhões }\end{array}$ & Prejuízo de R\$ 137,9 milhões \\
\hline Investimentos em TI & $\mathrm{R} \$ 70$ milhões & R\$ 20 milhões & R\$ 25 milhões \\
\hline
\end{tabular}

REAd | Porto Alegre - Edição 81 - N 2 - maio/agosto 2015 - p. 515-547 
Cláudio Luís Carvalho Larieira \& Alberto Luiz Albertin

\begin{tabular}{|c|c|c|c|}
\hline em 2012 & & & \\
\hline Estratégia declarada & $\begin{array}{l}\text { Dobrar a carteira de clientes } \\
\text { nos próximos } 3 \text { (três) anos }\end{array}$ & $\begin{array}{l}\text { Dobrar a carteira de clientes } \\
\text { nos próximos } 3 \text { (três) anos }\end{array}$ & $\begin{array}{l}\text { Diminuir até o fim de } 2013 \text { a } \\
\text { carteira de } 2 \text { mil clientes para } \\
800 \text { a } 1000 \text { clientes com maior } \\
\text { rentabilidade e menor risco de } \\
\text { inadimplência }\end{array}$ \\
\hline $\begin{array}{l}\text { Planejamento } \\
\text { Estratégico }\end{array}$ & $\begin{array}{l}\text { Possui planejamento } \\
\text { estratégico formalmente } \\
\text { definido, mas não é } \\
\text { divulgado para todos os } \\
\text { níveis gerenciais }\end{array}$ & $\begin{array}{l}\text { Não possui planejamento } \\
\text { estratégico formalmente } \\
\text { estabelecido, as discussões } \\
\text { estratégicas são realizadas } \\
\text { apenas pela alta liderança }\end{array}$ & $\begin{array}{l}\text { Não possui planejamento } \\
\text { estratégico formalmente } \\
\text { estabelecido, as discussões } \\
\text { estratégicas são realizadas } \\
\text { apenas pela alta liderança }\end{array}$ \\
\hline $\begin{array}{l}\text { Estágio do uso da TI } \\
\text { (NOLAN, 1979) }\end{array}$ & $\begin{array}{l}\text { Se encontra no Estágio de } \\
\text { Maturidade }\end{array}$ & $\begin{array}{l}\text { Se encontra no Estágio de } \\
\text { Maturidade }\end{array}$ & $\begin{array}{l}\text { Se encontra no Estágio de } \\
\text { Maturidade }\end{array}$ \\
\hline Governança de TI & $\begin{array}{l}\text { Implantou algumas boas } \\
\text { práticas, mas sem utilizar } \\
\text { modelos }\end{array}$ & $\begin{array}{l}\text { Não foram encontradas } \\
\text { práticas a respeito de } \\
\text { Governança de TI }\end{array}$ & $\begin{array}{l}\text { Elaborou e estabeleceu um } \\
\text { PDTI e implantou boas } \\
\text { práticas. }\end{array}$ \\
\hline Escritório de Projetos & Não possui & $\begin{array}{l}\text { Possui um Escritório de } \\
\text { Projetos voltado para projetos } \\
\text { de TIC }\end{array}$ & Não possui \\
\hline
\end{tabular}

Fonte: Dados da pesquisa

A tabela abaixo consolida os dados obtidos nas entrevistas com os Bancos X, Y e Z. Os respondentes foram agrupados por Demandantes, Executores e Decisores e foram listadas para cada fator organizacional as notas atribuídas pelos 20 (vinte) respondentes. Foram então calculadas as médias aritméticas de cada fator organizacional, assim como as médias dos agrupamentos dos respondentes e a média total geral dos respondentes.

Através da análise das médias percebe-se que, mesmo sendo os respondentes provenientes de organizações diferentes, os Demandantes e os Decisores são os respondentes que possuem as opiniões mais homogêneas entre si. Os Demandantes são os que mais percebem as influências dos fatores organizacionais sobre a GPPTIC (com 4,3 pontos de média), seguidos pelos Decisores (com 4,1 pontos de média) e pelos Executores (com 3,9 pontos de média).

Os Demandantes percebem maior influência dos fatores organizacionais porque eles pertencem ao grupo que possui o maior interesse para que os projetos de TIC sejam 
UM ESTUDO SOBRE OS FATORES ORGANIZACIONAIS QUE INFLUENCIAM A GESTÃO DE PORTFÓLIO DE PROJETOS DE TECNOLOGIA DA INFORMAÇÃO E COMUNICAÇÃO

selecionados e desenvolvidos nos bancos. Conforme levantado, também são o grupo que mais se envolve com o processo de GPPTIC dada suas responsabilidades em levantar informações, estruturar propostas e defender os projetos nos Comitês de Projetos. Neste sentido, além de os Demandantes terem que enfrentar a burocracia organizacional interna e do processo de GPPTIC, há a escassez de recursos que diminui as chances de ter seus projetos aprovados. 
Tabela 1 - Fatores organizacionais e suas influências sobre a GPPTIC.

\begin{tabular}{|c|c|c|c|c|c|c|c|c|c|c|c|c|c|c|c|c|c|c|c|c|c|c|c|c|}
\hline \multirow{2}{*}{$\begin{array}{c}\text { Fatores Organizaconais em GPPTIC e suas } \\
\text { influências }\end{array}$} & \multicolumn{3}{|c|}{ Demandantes $\mathrm{X}$} & \multicolumn{2}{|c|}{ Demandantes $Y$} & \multicolumn{2}{|c|}{ Demandantes Z } & \multirow{2}{*}{$\begin{array}{c}\text { Média } \\
\text { Demandantes }\end{array}$} & \multicolumn{3}{|c|}{ Executores $\mathrm{X}$} & \multicolumn{2}{|c|}{ Executores $Y$} & \multicolumn{2}{|c|}{ Executores Z } & \multirow{2}{*}{$\begin{array}{c}\text { Média } \\
\text { Executores }\end{array}$} & \multicolumn{2}{|c|}{ Decisores $X$} & \multicolumn{2}{|c|}{ Decisores Y } & \multicolumn{2}{|c|}{ Decisores Z } & \multirow{2}{*}{\begin{tabular}{|c|} 
Média \\
Decisores \\
\end{tabular}} & \multirow{2}{*}{$\begin{array}{c}\text { Médias } \\
\text { Finais }\end{array}$} \\
\hline & Dem.X1 & Dem. X2 & Dem. X3 & Dem. Y1 & Dem. Y2 & Dem.Z1 & Dem. Z2 & & Exec. X1 & Exec. $\times 2$ & Exec. X3 & Exec. Y1 & Exec. Y2 & Exec. Z1 & Exec. Z2 & & Dec. X1 & Dec. X2 & Dec.Y1 & Dec. Y2 & Dec. Z1 & Dec. Z2 & & \\
\hline Recursos & 5,0 & 4,3 & 3,7 & 4,7 & 4,3 & 4,3 & 3,7 & 4,3 & 4,3 & 3,0 & 4,3 & 4,7 & 4,3 & 4,0 & 2,7 & 3,9 & 4,0 & 4,0 & 4,3 & 4,0 & 4,0 & 4,3 & 4,1 & 4,1 \\
\hline \begin{tabular}{|l|} 
Compartilhamento dos Recursos \\
\end{tabular} & 5,0 & 5,0 & 5,0 & 5,0 & 5,0 & 4,0 & 4,0 & 4,7 & 5,0 & 3,0 & 5,0 & 5,0 & 4,0 & 4,0 & 4,0 & 4,3 & 4,0 & 5,0 & 5,0 & 4,0 & 5,0 & 5,0 & 4,7 & 4,6 \\
\hline Disponibilidade de Recursos & 5,0 & 5,0 & 3,0 & 5,0 & 5,0 & 5,0 & 4,0 & 4,6 & 5,0 & 3,0 & 5,0 & 5,0 & 5,0 & 5,0 & 2,0 & 4,3 & 5,0 & 4,0 & 5,0 & 5,0 & 5,0 & 5,0 & 4,8 & 4,6 \\
\hline Ferramentas de Apoio & 5,0 & 3,0 & 3,0 & 4,0 & 3,0 & 4,0 & 3,0 & 3,6 & 3,0 & 3,0 & 3,0 & 4,0 & 4,0 & 3,0 & 2,0 & 3,1 & 3,0 & 3,0 & 3,0 & 3,0 & 2,0 & 3,0 & 2,8 & 3,2 \\
\hline Informações & 4,0 & 4,3 & 4,3 & 4,7 & 3,0 & 4,3 & 3,7 & 4,0 & 3,7 & 4,3 & 4,7 & 4,0 & 4,3 & 3,3 & 4,0 & 4,0 & 4,7 & 3,0 & 4,0 & 4,7 & 3,3 & 3,3 & 3,8 & 4,0 \\
\hline \begin{tabular}{|l|} 
Qualidade das Informações dos Projetos \\
\end{tabular} & 4,0 & 5,0 & 5,0 & 5,0 & 3,0 & 5,0 & 4,0 & 4,4 & 5,0 & 5,0 & 5,0 & 5,0 & 5,0 & 4,0 & 5,0 & 4,9 & 5,0 & 3,0 & 5,0 & 5,0 & 3,0 & 4,0 & 4,2 & 4,5 \\
\hline Qualidade das Informações sobre o Negócio & 4,0 & 5,0 & 5,0 & 5,0 & 4,0 & 5,0 & 4,0 & 4,6 & 5,0 & 5,0 & 5,0 & 4,0 & 4,0 & 3,0 & 5,0 & 4,4 & 5,0 & 4,0 & 5,0 & 5,0 & 4,0 & 3,0 & 4,3 & 4,4 \\
\hline Qualidade dos Dados Históricos & 4,0 & 3,0 & 3,0 & 4,0 & 2,0 & 3,0 & 3,0 & 3,1 & 1,0 & 3,0 & 4,0 & 3,0 & 4,0 & 3,0 & 2,0 & 2,9 & 4,0 & 2,0 & 2,0 & 4,0 & 3,0 & 3,0 & 3,0 & 3,0 \\
\hline Pessoas & 4,0 & 5,0 & 4,3 & 4,3 & 4,3 & 5,0 & 4,0 & 4,4 & 3,7 & 3,7 & 4,0 & 4,0 & 4,0 & 4,0 & 3,7 & 3,9 & 3,3 & 3,3 & 4,3 & 4,0 & 3,7 & 4,0 & 3,8 & 4,0 \\
\hline \begin{tabular}{|l|l|l} 
Engajamento dos Participantes \\
\end{tabular} & 5,0 & 5,0 & 5,0 & 5,0 & 5,0 & 5,0 & 5,0 & 5,0 & 5,0 & 4,0 & 5,0 & 5,0 & 5,0 & 5,0 & 5,0 & 4,9 & 5,0 & 4,0 & 4,0 & 5,0 & 4,0 & 4,0 & 4,3 & 4,7 \\
\hline Conhecimento sobre GPPTIC & 4,0 & 5,0 & 3,0 & 5,0 & 5,0 & 5,0 & 4,0 & 4,4 & 5,0 & 4,0 & 4,0 & 4,0 & 4,0 & 4,0 & 3,0 & 4,0 & 2,0 & 3,0 & 5,0 & 3,0 & 4,0 & 5,0 & 3,7 & 4,0 \\
\hline Conhecimento sobre TIC & 3,0 & 5,0 & 5,0 & 3,0 & 3,0 & 5,0 & 3,0 & 3,9 & 1,0 & 3,0 & 3,0 & 3,0 & 3,0 & 3,0 & 3,0 & 2,7 & 3,0 & 3,0 & 4,0 & 4,0 & 3,0 & 3,0 & 3,3 & 3,3 \\
\hline Organização & 2,8 & 4,0 & 4,0 & 4,3 & 5,0 & 4,3 & 4,0 & 4,0 & 3,5 & 3,5 & 3,8 & 3,5 & 3,8 & 3,0 & 4,3 & 3,6 & 3,8 & 4,3 & 3,3 & 3,5 & 5,0 & 4,8 & 4,1 & 3,9 \\
\hline \begin{tabular}{|l|} 
Porte da Organização \\
\end{tabular} & 3,0 & 3,0 & 5,0 & 3,0 & 5,0 & 4,0 & 4,0 & 3,9 & 1,0 & 5,0 & 5,0 & 4,0 & 4,0 & 2,0 & 4,0 & 3,6 & 4,0 & 4,0 & 5,0 & 3,0 & 5,0 & 5,0 & 4,3 & 3,9 \\
\hline Grau de Formalidade & 2,0 & 5,0 & 5,0 & 4,0 & 5,0 & 5,0 & 4,0 & 4,3 & 5,0 & 3,0 & 3,0 & 4,0 & 3,0 & 4,0 & 4,0 & 3,7 & 4,0 & 4,0 & 2,0 & 3,0 & 5,0 & 4,0 & 3,7 & 3,9 \\
\hline Disposição ao Risco & 3,0 & 5,0 & 3,0 & 5,0 & 5,0 & 4,0 & 4,0 & 4,1 & 5,0 & 3,0 & 3,0 & 3,0 & 4,0 & 3,0 & 4,0 & 3,6 & 3,0 & 5,0 & 2,0 & 4,0 & 5,0 & 5,0 & 4,0 & 3,9 \\
\hline Granularidade dos Projetos & 3,0 & 3,0 & 3,0 & 5,0 & 5,0 & 4,0 & 4,0 & 3,9 & 3,0 & 3,0 & 4,0 & 3,0 & 4,0 & 3,0 & 5,0 & 3,6 & 4,0 & 4,0 & 4,0 & 4,0 & 5,0 & 5,0 & 4,3 & 3,9 \\
\hline Processos & 2,6 & 5,0 & 5,0 & 4,8 & 3,6 & 4,6 & 4,4 & 4,3 & 4,4 & 3,2 & 3,4 & 4,6 & 4,8 & 3,6 & 4,6 & 4,1 & 4,6 & 3,8 & 4,8 & 4,4 & 3,4 & 4,0 & 4,2 & 4,2 \\
\hline \begin{tabular}{|l|l} 
Conflito Operaçoes X Projetos \\
\end{tabular} & 2,0 & 5,0 & 5,0 & 4,0 & 4,0 & 5,0 & 5,0 & 4,3 & 4,0 & 3,0 & 4,0 & 5,0 & 5,0 & 4,0 & 5,0 & 4,3 & 5,0 & 4,0 & 5,0 & 5,0 & 5,0 & 5,0 & 4,8 & 4,5 \\
\hline Maturidade da GP & 2,0 & 5,0 & 5,0 & 5,0 & 3,0 & 4,0 & 4,0 & 4,0 & 5,0 & 3,0 & 3,0 & 5,0 & 5,0 & 3,0 & 5,0 & 4,1 & 5,0 & 4,0 & 4,0 & 5,0 & 5,0 & 4,0 & 4,5 & 4,2 \\
\hline Maturidade da GPPTIC & 2,0 & 5,0 & 5,0 & 5,0 & 3,0 & 4,0 & 5,0 & 4,1 & 5,0 & 3,0 & 3,0 & 5,0 & 5,0 & 3,0 & 5,0 & 4,1 & 4,0 & 4,0 & 5,0 & 4,0 & 3,0 & 4,0 & 4,0 & 4,1 \\
\hline Transparência da GPPTIC & 4,0 & 5,0 & 5,0 & 5,0 & 5,0 & 5,0 & 4,0 & 4,7 & 4,0 & 4,0 & 4,0 & 4,0 & 5,0 & 4,0 & 4,0 & 4,1 & 4,0 & 3,0 & 5,0 & 5,0 & 2,0 & 4,0 & 3,8 & 4,2 \\
\hline \begin{tabular}{|l} 
Continuidade do Processo \\
\end{tabular} & 3,0 & 5,0 & 5,0 & 5,0 & 3,0 & 5,0 & 4,0 & 4,3 & 4,0 & 3,0 & 3,0 & 4,0 & 4,0 & 4,0 & 4,0 & 3,7 & 5,0 & 4,0 & 5,0 & 3,0 & 2,0 & 3,0 & 3,7 & 3,9 \\
\hline Politica & 4,8 & 4,5 & 4,0 & 3,8 & 5,0 & 4,3 & 4,3 & 4,4 & 3,5 & 3,5 & 3,3 & 4,8 & 4,8 & 3,0 & 4,0 & 3,8 & 5,0 & 4,0 & 4,0 & 4,0 & 5,0 & 4,5 & 4,4 & 4,2 \\
\hline \begin{tabular}{|l|} 
Apoio da Liderança \\
\end{tabular} & 5,0 & 5,0 & 5,0 & 5,0 & 5,0 & 5,0 & 5,0 & 5,0 & 5,0 & 2,0 & 1,0 & 5,0 & 5,0 & 4,0 & 5,0 & 3,9 & 5,0 & 5,0 & 5,0 & 4,0 & 5,0 & 5,0 & 4,8 & 4,6 \\
\hline Resistência das Pessoas & 5,0 & 5,0 & 5,0 & 3,0 & 5,0 & 3,0 & 4,0 & 4,3 & 3,0 & 5,0 & 5,0 & 5,0 & 5,0 & 2,0 & 4,0 & 4,1 & 5,0 & 3,0 & 3,0 & 3,0 & 5,0 & 4,0 & 3,8 & 4,1 \\
\hline Integração entre as Áreas & 5,0 & 5,0 & 3,0 & 3,0 & 5,0 & 4,0 & 4,0 & 4,1 & 3,0 & 4,0 & 4,0 & 4,0 & 4,0 & 3,0 & 4,0 & 3,7 & 5,0 & 4,0 & 4,0 & 4,0 & 5,0 & 4,0 & 4,3 & 4,1 \\
\hline \begin{tabular}{|l|l|} 
Competição entre os Projetos \\
\end{tabular} & 4,0 & 3,0 & 3,0 & 4,0 & 5,0 & 5,0 & 4,0 & 4,0 & 3,0 & 3,0 & 3,0 & 5,0 & 5,0 & 3,0 & 3,0 & 3,6 & 5,0 & 4,0 & 4,0 & 5,0 & 5,0 & 5,0 & 4,7 & 4,1 \\
\hline Estratégias & 4,3 & 4,5 & 4,0 & 4,5 & 4,5 & 5,0 & 4,3 & 4,4 & 4,0 & 3,5 & 3,8 & 4,5 & 4,8 & 3,3 & 4,0 & 4,0 & 4,8 & 4,0 & 3,5 & 4,0 & 4,5 & 4,8 & 4,3 & 4,2 \\
\hline Alinhamento Estratégico & 4,0 & 5,0 & 5,0 & 5,0 & 4,0 & 5,0 & 4,0 & 4,6 & 5,0 & 4,0 & 3,0 & 5,0 & 5,0 & 2,0 & 5,0 & 4,1 & 5,0 & 4,0 & 2,0 & 3,0 & 5,0 & 5,0 & 4,0 & 4,2 \\
\hline Visão Compartilhada & 3,0 & 5,0 & 5,0 & 5,0 & 5,0 & 5,0 & 4,0 & 4,6 & 4,0 & 3,0 & 3,0 & 5,0 & 5,0 & 3,0 & 3,0 & 3,7 & 4,0 & 4,0 & 5,0 & 5,0 & 4,0 & 4,0 & 4,3 & 4,2 \\
\hline Estratégia de TIC & 5,0 & 3,0 & 3,0 & 4,0 & 4,0 & 5,0 & 5,0 & 4,1 & 5,0 & 3,0 & 4,0 & 4,0 & 5,0 & 4,0 & 5,0 & 4,3 & 5,0 & 3,0 & 2,0 & 4,0 & 4,0 & 5,0 & 3,8 & 4,1 \\
\hline Papel da TIC na Organização & 5,0 & 5,0 & 3,0 & 4,0 & 5,0 & 5,0 & 4,0 & 4,4 & 2,0 & 4,0 & 5,0 & 4,0 & 4,0 & 4,0 & 3,0 & 3,7 & 5,0 & 5,0 & 5,0 & 4,0 & 5,0 & 5,0 & 4,8 & 4,3 \\
\hline Gestão & 5,0 & 4,6 & 3,8 & 4,0 & 4,2 & 4,8 & 4,2 & 4,4 & 4,4 & 2,8 & 3,8 & 4,6 & 4,6 & 3,6 & 4,2 & 4,0 & 4,4 & 3,6 & 4,6 & 3,8 & 4,6 & 4,2 & 4,2 & 4,2 \\
\hline \begin{tabular}{|l|} 
Governança do Processo \\
\end{tabular} & 5,0 & 5,0 & 3,0 & 5,0 & 3,0 & 5,0 & 4,0 & 4,3 & 5,0 & 4,0 & 4,0 & 5,0 & 5,0 & 4,0 & 4,0 & 4,4 & 5,0 & 3,0 & 5,0 & 5,0 & 5,0 & 4,0 & 4,5 & 4,4 \\
\hline Estabilidade da Gestão & 5,0 & 5,0 & 3,0 & 5,0 & 5,0 & 4,0 & 4,0 & 4,4 & 3,0 & 3,0 & 3,0 & 5,0 & 4,0 & 4,0 & 3,0 & 3,6 & 4,0 & 4,0 & 3,0 & 5,0 & 5,0 & 5,0 & 4,3 & 4,1 \\
\hline Papéis e Responsabilidades & 5,0 & 5,0 & 5,0 & 4,0 & 5,0 & 5,0 & 5,0 & 4,9 & 5,0 & 3,0 & 3,0 & 5,0 & 5,0 & 4,0 & 5,0 & 4,3 & 5,0 & 4,0 & 5,0 & 4,0 & 5,0 & 4,0 & 4,5 & 4,5 \\
\hline Status dos Gestores de TIC & 5,0 & 5,0 & 5,0 & 2,0 & 3,0 & 5,0 & 4,0 & 4,1 & 5,0 & 1,0 & 5,0 & 4,0 & 4,0 & 3,0 & 4,0 & 3,7 & 3,0 & 4,0 & 5,0 & 2,0 & 4,0 & 4,0 & 3,7 & 3,8 \\
\hline \begin{tabular}{|l|} 
Suporte Organizacional \\
\end{tabular} & 5,0 & 3,0 & 3,0 & 4,0 & 5,0 & 5,0 & 4,0 & 4,1 & 4,0 & 3,0 & 4,0 & 4,0 & 5,0 & 3,0 & 5,0 & 4,0 & 5,0 & 3,0 & 5,0 & 3,0 & 4,0 & 4,0 & 4,0 & 4,0 \\
\hline Médias dos respondentes & 4,0 & 4,5 & 4,1 & 4,4 & 4,2 & 4,6 & 4,1 & 4,3 & 3,9 & 3,4 & 3,9 & 4,3 & 4,4 & 3,5 & 3,9 & 3,9 & 4,3 & 3,7 & 4,1 & 4,0 & 4,2 & 4,2 & 4,1 & 4,1 \\
\hline
\end{tabular}

Fonte: Dados da pesquisa

REAd | Porto Alegre - Edição 81 - Nº 2 - maio/agosto 2015 - p. 515-547 
Os Decisores, comparativamente, assumem uma postura mais passiva em relação a este processo já que suas participações se restringem às reuniões de Comitê de Projeto. Há um fato que foi levantado nos casos individuais e que deve ser denotado: os Decisores dos bancos estudados têm enfrentado grande dificuldade na decisão sobre quais projetos de TIC selecionar por conta da Crise Mundial de 2008 que fez com que os orçamentos tenham diminuído a cada ano.

Os Executores entrevistados possuem níveis diferentes de interação nos bancos em que atuam. Em geral, eles participam no processo de GPPTIC com menor intensidade e menor frequência quando comparados aos Demandantes e Decisores. Por vezes, inclusive, eles apenas recebem os resultados do processo que foi executado para a seleção dos projetos, não tomando parte ativa no processo. Isto se explica pelo fato de que nas organizações estudadas o modelo implementado de decisão e implementação de TIC segue a lógica da Execução de Estratégia proposta por Henderson e Venkatraman (1993) na qual as decisões de TIC obedecem às decisões de negócio.

Com o intuito de identificar os fatores organizacionais que tem maior e menor influência sobre a GPPTIC nos bancos analisados foi criada a tabela 2. Esta tabela classifica os fatores organizacionais segundo suas respectivas médias e os apresenta em ordem decrescente. Nos parágrafos que se seguem são apresentados os 4 (quatro) fatores organizacionais que mais influenciam a GPPTIC e os 3 (três) fatores organizacionais que menos influenciam a GPPTIC.

O Engajamento dos Participantes é o fator organizacional que foi apurado como o mais influente sobre a GPPTIC. A baixa adesão de participantes ou de áreas importantes à execução do processo ou a "sabotagem" de alguns gestores importantes às decisões tomadas pelos Comitês de Projetos levam a uma situação de descrença sobre o valor deste processo nas organizações. Some-se a isto o fato de o processo se tornar mais longo e mais caro. Assim, é preciso que os gestores do processo de GPPTIC “evangelizem” constantemente as áreas e pessoas importantes neste processo para que se obtenha deles o engajamento e comprometimento necessários (ENGLUND e GRAHAM, 1999; JAYME et al, 2006) (SHAH e NAQVI, 2014). 
Cláudio Luís Carvalho Larieira \& Alberto Luiz Albertin

Tabela 2 - Ranking dos Fatores Organizacionais conforme suas influências

\begin{tabular}{|c|c|}
\hline $\begin{array}{l}\text { Ranking dos Fatores Organizaconais em } \\
\text { GPPTIC e suas influências }\end{array}$ & Médias \\
\hline Engajamento dos Participantes & 4,7 \\
\hline Disponibilidade de Recursos & 4,6 \\
\hline Apoio da Liderança & 4,6 \\
\hline Compartilhamento dos Recursos & 4,6 \\
\hline Papéis e Responsabilidades & 4,5 \\
\hline Qualidade das Informações dos Projetos & 4,5 \\
\hline Conflito Operações X Projetos & 4,5 \\
\hline Qualidade das Informações sobre o Negócio & 4,4 \\
\hline Governança do Processo & 4,4 \\
\hline Papel da TIC na Organização & 4,3 \\
\hline Alinhamento Estratégico & 4,2 \\
\hline Transparência da GPPTIC & 4,2 \\
\hline Maturidade da GP & 4,2 \\
\hline Visão Compartilhada & 4,2 \\
\hline Estabilidade da Gestão & 4,1 \\
\hline Maturidade da GPPTIC & 4,1 \\
\hline Resistência das Pessoas & 4,1 \\
\hline Estratégia de TIC & 4,1 \\
\hline Competição entre os Projetos & 4,1 \\
\hline Integração entre as Áreas & 4,1 \\
\hline Suporte Organizacional & 4,0 \\
\hline Conhecimento sobre GPPTIC & 4,0 \\
\hline Porte da Organização & 3,9 \\
\hline Granularidade dos Projetos & 3,9 \\
\hline Disposição ao Risco & 3,9 \\
\hline Continuidade do Processo & 3,9 \\
\hline Grau de Formalidade & 3,9 \\
\hline Status dos Gestores de TIC & 3,8 \\
\hline Conhecimento sobre TIC & 3,3 \\
\hline Ferramentas de Apoio & 3,2 \\
\hline Qualidade dos Dados Históricos & 3,0 \\
\hline
\end{tabular}

Fonte: Dados da pesquisa.

Um dos executores entrevistado comentou sobre o engajamento dos participantes:

Aqui no banco cada um trabalha por si. Eu falo com propriedade: eu cheguei aqui há um ano e eu percebi que o grande medo aqui é perder o emprego. Então é muito difícil pegar uma informação, cada um puxa pro seu lado. Às vezes tem reunião e as pessoas não vão e nem passam informação, tem que ficar pedindo prá diretor ajudar. Eu tive um projeto que a gente teve que cancelar, porque não andava.

Um dos demandantes também comentou a respeito:

Às vezes as pessoas vão nas reuniões dos projetos e não sabem nem o que está acontecendo, porque elas não se engajaram antes, Às vezes elas vão nas reuniões e 
UM ESTUDO SOBRE OS FATORES ORGANIZACIONAIS QUE INFLUENCIAM A GESTÃO DE PORTFÓLIO DE PROJETOS DE TECNOLOGIA DA INFORMAÇÃO E COMUNICAÇÃO

querem decidir tudo, mas elas não conhecem nenhum projeto, ai a gente começa falar de um projeto, leva duas horas falando do mesmo projeto e acaba não decidindo nada. Mas por quê? Porque ninguém sabia o que estava acontecendo, quer dizer, ninguém correu atrás antes.

Os autores que abordam o fator Disponibilidade de Recursos recomendam que as organizações efetuem um levantamento prévio dos recursos disponíveis para determinar a capacidade de desenvolver novos projetos (ENGLUND e GRAHAM, 1999; DOOLEY, LUPTON e O'SULLIVAN, 2005), o que foi identificado que não acontece em nenhum dos bancos analisados. Com isto, surge nestes bancos o problema da "Síndrome de Alocação de Recursos" (ENGWALL e JERBRANT, 2003; DOOLEY, LUPTON e O'SULLIVAN, 2005), neste caso nem tanto pela escassez dos recursos, mas muito mais pela falta de conhecimento sobre o quanto se tem de fato de recursos disponíveis para os projetos a exemplo das palavras de um dos executores entrevistados:

Hoje faltam recursos no banco para fazer tantos projetos. Ai junta com o crescimento dos projetos pedidos pelas áreas de negócio prá poder dar conta da reestruturação que o banco está fazendo, fica mais difícil ainda. Outra coisa também é que as áreas pedem projetos, mas eles não sabem se a TI pode atender ou não.

O Apoio da Liderança, segundo os autores estudados, é o fator que se relaciona com o apoio que os líderes devem dar ao processo de GPP para que este não venha a sofrer boicotes durante sua execução e acompanhamento (DOOLEY, LUPTON e O'SULLIVAN, 2005; JAYME et al, 2006). De maneira geral, os entrevistados dos bancos reconhecem que suas lideranças tem prestado este apoio e a falta dele traz naturalmente muitas dificuldades para a execução da GPPTIC. O fato curioso aconteceu no Banco Z, onde os respondentes comentaram que a alta direção do banco (no caso, os sócios) interfere com certa frequência nos resultados deste processo (ainda que haja um processo estabelecido formalmente para avaliar, selecionar e priorizar os projetos de TIC a serem desenvolvidos pelo banco). Estas ingerências acabam gerando um clima de insatisfação dos participantes do processo que se sentem "desvalorizados e desacreditados" perante o restante do banco, o que se traduz na falta de apoio da liderança, implicitamente.

Como parte do mesmo problema que trata de recursos está o fator intitulado de Compartilhamento dos Recursos, que se configura como a dificuldade que os gestores têm em conseguir equilíbrio entre os recursos demandados pelos projetos e recursos disponíveis (COOPER, EDGETT e KLEINSCHIMIDT, 2001; ENGWALL e JERBRANT, 2003;

REAd | Porto Alegre - Edição 81 - N 2 - maio/agosto 2015 - p. 515-547 
DOOLEY, LUPTON e O'SULLIVAN, 2005; PENNYPACKER, 2005). Tendo muitos projetos ao mesmo tempo e sem o conhecimento adequado da capacidade disponível de recursos, os resultados das pesquisas demonstraram que os bancos analisados tem grande dificuldade em gerenciar este tipo de problema. Os respondentes declararam que os bancos implementam modelos matriciais de alocação de recursos e isto aumenta a complexidade de alocação dos recursos. O efeito percebido é de que os profissionais tem dificuldade em priorizar suas ações nos projetos, o que acaba por gerar atrasos e consequente perda de foco na realização do portfólio de projetos.

Por exemplo, um dos demandantes fez a seguinte ponderação:

A gente sabe que às vezes este compartilhamento complica muito, porque dependendo da demanda que é, são demandas que são muito importantes, às vezes são duas demandas importantes que estão com a mesma pessoa [...] e ai você é cobrado e só tem uma pessoa prá fazer aquilo, então o portfólio de projetos não acontece.

Um decisor também alegou que este fator organizacional influencia fortemente a GPPTIC porque

No momento atual do banco isto tem uma forte relevância, porque eu tenho um portfólio extenso de projetos onde a gente até brinca aqui que o trem tem que caminhar em paralelo e eu tenho, por exemplo, quatro grandes projetos que são estratégicos e meus recursos são escassos [...] e o pior, compartilhados [...] eu tô aqui numa briga pesada, porque eu tenho mais projeto do que gente e eu tenho este compartilhamento de recursos que aqui me gera um grande problema [...] às vezes você compartilha o mesmo recurso entre eles e cada um tem seu nível de prioridade e ai fica muito complexo [...] ai falta foco, falta assertividade.

São apresentados a partir deste ponto os fatores organizacionais percebidos com menor influência sobre a GPPTIC, listados em ordem decrescente. O Conhecimento sobre TIC foi avaliado nos 3 (três) bancos como um dos fatores organizacionais menos influentes sobre a GPPTIC. As questões técnicas não fazem parte das discussões sobre o portfólio de projetos e portanto não trazem grande impacto às decisões de avaliação e seleção. Não significa dizer que não haja a necessidade de os gestores conhecerem TIC, mas conforme exemplificou o Executor 1 do Banco Z, “as pessoas atualmente já possuem certo domínio de TI, então elas conseguem definir e opinar sobre projetos de TI", o que então em sua percepção gera pouco impacto sobre a GPPTIC. Segundo o Decisor 1 deste mesmo banco, o fato de as atividades de gestão de projeto e de portfólio serem segmentadas por áreas especialistas diminui a necessidade de se ter Demandantes e Decisores com bom conhecimento de TIC no banco. 
UM ESTUDO SOBRE OS FATORES ORGANIZACIONAIS QUE INFLUENCIAM A GESTÃO DE PORTFÓLIO DE PROJETOS DE TECNOLOGIA DA INFORMAÇÃO E COMUNICAÇÃO

Englund e Graham (1999) recomendam que sejam adotadas Ferramentas de Apoio na forma de sistemas ou aplicações de software para suportar o processo de GPP. Como os bancos estudados tem um nível baixo de maturidade da GPPTIC, seus respondentes consideram que possuir ferramentas para realizar o processo ajuda, mas não define seu sucesso, por isto a influência tida como moderada para este fator organizacional.

Por último, é apresentado o fator organizacional que talvez tenha causado mais estranheza pela divergência de percepção entre os autores e a resposta do campo: a Qualidade dos Dados Históricos. Alguns autores defendem que, além de informações sobre os projetos em análise e do negócio, é necessário que se tenha uma boa base de dados contendo as informações dos projetos passados (ENGLUND e GRAHAM, 1999; JEFFERY e LELIVELD, 2004; MOECKEL e FORCELLINI, 2009). Estes dados históricos ajudariam a realizar estimativas e simulações confiáveis para definir prazos e recursos para os novos projetos. Porém, por mais óbvio que possa parecer este conceito, os respondentes dos bancos consideram que dados históricos têm certa limitação atualmente em termos de preparação e execução das atividades de avaliação e seleção dos projetos. Segundo alguns entrevistados, é mais importante ter clareza do cenário atual e futuro dos projetos e do negócio, ao ponto que os dados históricos exercem um papel secundário nas análises e tomadas de decisão. Neste aspecto, os respondentes concordam que utilizam pouco das lições aprendidas que os projetos passados poderiam trazer ao processo de GPPTIC. Em suas percepções, os projetos dos bancos são geralmente situações novas, ainda não vividas, e portanto não trazem contribuições os dados históricos ao processo de GPPTIC.

Em relação aos agrupamentos dos fatores organizacionais (conforme tabela 3 abaixo), pode-se afirmar que os agrupamentos possuem similaridade de influência sobre a GPPTIC, pois há pequena variação de pontuação entre eles. Desta forma, cabe aqui mencionar que o agrupamento de Políticas possui a média de 4,2 pontos e que o fator organizacional com maior pontuação neste agrupamento é o Apoio da Liderança (que foi avaliado pelos respondentes como um dos mais influentes fatores).

Dois outros agrupamentos que possuem a média de 4,2 pontos devem ser destacados aqui: (i) o agrupamento de Gestão, que possui o fator organizacional denominado de Papéis e Responsabilidades como o fator com maior pontuação e (ii) Processos, que possui o fator organizacional denominado de Conflito Operações X Projetos como o fator de maior pontuação. 
Cláudio Luís Carvalho Larieira \& Alberto Luiz Albertin

Tabela 3 - Ranking dos Fatores Organizacionais por Agrupamento

\begin{tabular}{|l|c|c|}
\hline $\begin{array}{c}\text { Ranking dos Agrupamentos dos Fatores } \\
\text { Organizaconais em GPPTIC }\end{array}$ & $\begin{array}{c}\text { Médias } \\
\text { Finais }\end{array}$ & $\begin{array}{c}\text { Maior média no } \\
\text { Agrupamento }\end{array}$ \\
\hline Política & $\mathbf{4 , 2}$ & $\mathbf{4 , 6}$ \\
\hline Gestão & $\mathbf{4 , 2}$ & $\mathbf{4 , 5}$ \\
\hline Processos & $\mathbf{4 , 2}$ & $\mathbf{4 , 5}$ \\
\hline Estratégias & $\mathbf{4 , 2}$ & $\mathbf{4 , 3}$ \\
\hline Recursos & $\mathbf{4 , 1}$ & $\mathbf{4 , 6}$ \\
\hline Pessoas & $\mathbf{4 , 0}$ & $\mathbf{4 , 7}$ \\
\hline Informações & $\mathbf{4 , 0}$ & $\mathbf{4 , 5}$ \\
\hline Organização & $\mathbf{3 , 9}$ & $\mathbf{3 , 9}$ \\
\hline
\end{tabular}

Fonte: Dados da pesquisa

Mesmo que as médias dos agrupamentos dos fatores organizacionais sejam bastante semelhantes em termos de resultado, é importante ressaltar que estas médias apresentam uma pontuação alta (entre 3,9 e 4,2 pontos) se considerado que a escala de valores estabelecida vai de 1,0 (um) a 5,0 (cinco) pontos. Em resumo, os agrupamentos se mostram como muito influentes sobre o processo de GPPTIC.

Por último, a média final apurada de todos os fatores organizacionais de 4,1 pontos revela que os fatores organizacionais nesta amostra de respondentes tem um alto poder de influência sobre a GPPTIC.

\section{CONSIDERAÇÕES FINAIS}

Este trabalho de pesquisa se propôs a estudar em organizações brasileiras os fatores organizacionais que podem influenciar o processo de Gestão de Portfólio de Projetos, mais especificamente para os projetos de TIC. Este estudo possibilitou: (i) identificar à luz da literatura estudada os fatores organizacionais que influenciam a GPPTIC; (ii) verificar através de estudos de caso em organizações brasileiras que os fatores organizacionais de fato estão presentes na GPPTIC; (iii) analisar as influências que os fatores organizacionais exercem sobre a GPPTIC e concluir que estes possuem uma influência de moderada a alta sobre o processo nas organizações. Conforme relatado, há indícios de que os fatores organizacionais têm considerável influência sobre este processo dados os resultados obtidos na pesquisa.

Considera-se então que foi cumprido plenamente o objetivo deste estudo. Além da REAd | Porto Alegre - Edição 81 - N² 2 - maio/agosto 2015 - p. 515-547 
UM ESTUDO SOBRE OS FATORES ORGANIZACIONAIS QUE INFLUENCIAM A GESTÃO DE PORTFÓLIO DE PROJETOS DE TECNOLOGIA DA INFORMAÇÃO E COMUNICAÇÃO

contribuição teórica que esta estrutura conceitual representa, do ponto de vista de aplicação prática ela oferece insumos às organizações e seus administradores que tenham a intenção de implantar a GPPTIC, pois apresenta elementos que transcendem às questões meramente técnicas de um processo.

Havia uma percepção inicial por parte dos autores de que o processo de GPPTIC, mais do que um processo operacional e mecânico, sofre com as influências que advém de questões políticas da organização, da disputa por recursos, de conflitos de interesse, de que há questões de poder envolvidas em sua execução, entre outras influências. Neste sentido, a percepção inicial dos autores considerava ser equivocado que uma organização ao adotar um processo como este se preocupasse apenas em definir um fluxo, implantar as ferramentas e treinar as pessoas para utilizá-lo. Estas atividades são importantes, mas não são suficientes para garantir a execução adequada do processo de GPPTIC em uma organização.

Respeitadas as limitações do estudo, foi confirmada a veracidade dos fatores organizacionais citados na literatura encontrada com relação à prática empresarial corrente, bem como a influência que estes exercem sobre a GPPTIC. Assim, a contribuição teórica deste trabalho de pesquisa se refere à criação de uma estrutura conceitual que estende os conceitos que envolvem a GPPTIC através da representação dos diversos fatores organizacionais que podem influenciar de alguma maneira este processo em uma organização. Cabe aqui mencionar que na literatura pesquisada não foram encontradas estruturas semelhantes à proposta neste estudo.

Um fato importante a ser denotado é que, quando aplicados os questionários nos estudos de caso realizados, foram obtidos resultados diferentes a respeito das influências dos fatores organizacionais nos Banco X, Y e Z. Estes resultados diferentes permitem afirmar que as organizações percebem as influências destes fatores organizacionais de modo diferente em função de seus históricos com este processo, suas escolhas de implementação, seus recursos (entre outras razões) e de que a estrutura conceitual propiciou a capacidade de generalização do problema.

Também é importante ressaltar que esta estrutura conceitual não tem por pretensão ser uma referência definitiva a respeito do tema dado que foi construída a partir de estudos de casos e com uma abordagem exploratória e qualitativa. Obviamente outras pesquisas devem ser realizadas para que esta estrutura se transforme de fato em um modelo mais robusto. Esta estrutura conceitual deve ser entendida como a base para estudos mais detalhados e 
aprofundados.

Com relação às limitações deste estudo deve-se salientar: (i) o método de pesquisa oferece menos possibilidades de generalização cientifica quando comparado a outros métodos de pesquisa, principalmente os quantitativos (YIN, 2010); (ii) não foi seguida uma lógica de amostragem para seleção dos respondentes, à semelhança do que acontece com trabalhos de pesquisa quantitativos e positivistas; (iii) a pesquisa foi realizada em um segmento de negócio específico e especificamente a respeito de projetos de TIC; (iv) foram considerados apenas os fatores internos à organização. Apesar das limitações aqui apresentadas, entende-se que a pesquisa obteve os resultados esperados e foi possível validar de maneira empírica nos 3 (três) estudos de caso realizados os fatores organizacionais sobre a GPPTIC encontrados na literatura consultada.

Por fim, algumas sugestões de estudos futuros são apresentadas: (i) realizar pesquisa em outros segmentos de negócio e em outros tipos de projeto, tendo como objetivo testar a validade da estrutura proposta; (ii) estender a estrutura proposta para incluir os fatores que são externos à organização; (iii) realizar uma pesquisa quantitativa para medir as influências organizacionais sobre a GPPTIC ajudará a transformar a estrutura em um modelo; (iv) foram encontrados poucos trabalhos que tratam das atividades de categorização de projetos e do balanceamento e do monitoramento da carteira de projetos; desta forma, é recomendado que estudos sejam conduzidos para determinar critérios para a categorização de projetos e para o balanceamento da carteira de projetos, bem como a pesquisa de técnicas para o monitoramento da carteira de projetos em alinhamento às mudanças de cenário do negócio.

\section{REFERÊNCIAS}

\section{ALBERTIN, A. L. Pesquisa FGV-EAESP de Comércio Eletrônico no Mercado Brasileiro - 15 . edição. São Paulo: FGV-EAESP, abril de 2013.}

ARCHER, N.P.; GHASEMZADEH, F. An integrated framework for project portfolio selection. International Journal of Project Management, Reino Unido, Vol. 17, nro. 4, p. 207216, 1999.

BARDIN, L. Análise de Conteúdo. Lisboa, Portugal: Edições 70, LDA, 2004. 
UM ESTUDO SOBRE OS FATORES ORGANIZACIONAIS QUE INFLUENCIAM A GESTÃO DE PORTFÓLIO DE PROJETOS DE TECNOLOGIA DA INFORMAÇÃO E COMUNICAÇÃO

BENBASAT, I.; GODLSTEIN, D. K.; MEAD, M. The Case Study Research Strategy in Studies of Information Systems. MIS Quarterly, nº 11, p. 369-386, 1987.

BONHAM, S. S. IT Project Portfolio Management. New York: Artech House, 2005.

CHRISTIANSEN, J. K.; VARNES, C. From models to practice: decision making at portfolio meetings. International Journal of Quality \& Reliability Management, Vol. 25, Nro. 1, p. 87-101, 2008.

COOPER, R. G.; EDGETT, S. J.; KLEINSCHIMIDT, E. J. Portfolio Management for New Product Development: Results of an industries practices study. R\&D Management, Vol. $31, n^{\circ} 4,2001$.

DINSMORE, P. C.; CABANIS-BREWIN, J. Manual de Gerenciamento de Projetos. Rio de Janeiro: American Management Association (AMA), 2009.

DOOLEY, L.; LUPTON, G.; O’SUlLIVAN, D. Multiple Project Management: a modern competitive necessity. Journal of Manufacturing Technology Management, Vol. 16, Nro. 5, p. 446-482, 2005.

DUBÉ, L.; PARÉ, G. Rigor in IS Positivist Case Research: Currents Practices, Trends, and Recommendations. MIS Quarterly, Vol. 27, Nro. 4, p. 597-635, December 2003.

EISENHARDT, K. M. Building Theories from Case Study Research. Academy of Management Review, Vol. 14, Nro. 4, p. 532-550, October 1989.

ENGLUND, R. L.; GRAHAM, R. J. From Experience: linking projects to strategy. Journal of Product Innovation Management. Vol. 16, Issue 1, Jan 1999, p. 52-64.

ENGWALL, M.; JERBRANT, A. The resource allocation syndrome: the prime challenge of multi-project management? International Journal of Project Management, Vol. 21, p. 403-409, 2003.

GHASEMZADEH, F.; ARCHER, N.P. Project portfolio selection trough decision support. Decision Support Systems, 2000, nro. 29, p. 73-88. 
Cláudio Luís Carvalho Larieira \& Alberto Luiz Albertin

GUEDES, R. M. et al. Alinhamento do portfólio de projetos à estratégia das organizações: um estudo exploratório quantitativo. In: XVI Simpósio de Administração da Produção, Logística e Operações Internacionais (SIMPOI), São Paulo, 2011.

HENDERSON, J. C.; VENKATRAMAN, N. Strategic Alignment: leveraging Information Technology for transforming organizations. IBM Systems Journal, Vol. 38, NOS 2\&3, 1993.

INTERNATIONAL DATA CORPORATION (IDC). Organizações brasileiras devem gastar US\$ 175 bi com TIC em 2014, diz IDC. São Paulo, 2014. Disponível em:

<http://computerworld.com.br/negocios/2014/02/05/organizações-brasileiras-devem-gastarus-175-bi-com-tic-em-2014-diz-idc/>. Acesso em: 27 jun. 2014.

JAYME, A. C. W. Z.; PERRONE, A.; MONTEIRO, O.; TORRES, T. C. R.; EICHMANN, V. Gestão de portfólio de projetos - Qual é o principal fator crítico para a gestão de portfólio de projetos no setor público e privado. 2006, 92 p. Monografia (Pós-graduação em Gerência de Projetos), Fundação Getulio Vargas, Curitiba, PR.

JEFFERY, M.; LELIVELD, I. Best Practices in IT Portfolio Management. Boston: MIT Sloan Management Review, 2004.

KAISER, M. G.; ARBI, F. E.; AHLEMANN, F. Sucessful Project Portfolio Management beyond project selection techniques: understanding the role of structural alignment. International Journal of Project Management, Reino Unido, Vol. 33, p. 126-139, 2014.

KERZNER, H. Gestão de projetos - As melhores práticas - $\mathbf{2}^{\mathrm{a}}$. edição. Porto Alegre: Bookman, 2006.

LARIEIRA, C. L. C.; Albertin, A. L. Gestão de Portfólio de Projetos: um Estudo Bibliométrico para exploração dos Avanços e Tendências na Pesquisa Acadêmica. In: 31․ ENEGEP, Belo Horizonte, 2011.

MAIZLISH, B.; HANDLER, R. IT Portfolio Management Step-by-Step: Unlocking the Business Value of IT. New York: John Wiley \& Sons, 2005.

MARTIN, C. C. Project Management: How to make it work. New York: AMACOM, 1976.

MCFARLAN, F. W.; MCKENNEY, J. L.; PYBURN, P. The information archipelago: plotting a course. Boston: Harvard Business Review, 1983. 
UM ESTUDO SOBRE OS FATORES ORGANIZACIONAIS QUE INFLUENCIAM A GESTÃO DE PORTFÓLIO DE PROJETOS DE TECNOLOGIA DA INFORMAÇÃO E COMUNICAÇÃO

MEREDITH, J. R.; MANTEL JR., S. J. Project Management: A Managerial Approach. Estados Unidos da América: John Wiley \& Sons, 1985.

MOECKEL, A.; FORCELlinI, F. A. Qualidade da Informação na Gestão de Portfólio durante o Planejamento Estratégico de Produtos. Revista Innovare, 8a. Edição, jul-dez, 2009.

MORAES, H. R. O. C.; GARCEZ, M. P. Project Portfolio Management Maturity and the Information Technology Role in Organizations: An Empirical Study. In: 11th International Conference on Information Systems and Technology Management CONTECSI, São Paulo, 2014.

NOLAN, R. L. Managing the crises in data processing. Boston: Harvard Business Review, 1979.

PENNYPACKER, J. S. PM Solutions' Project Portfolio Management Maturity Model. Center for Business Practices, Havertwon (Pennsylvania/USA), 2005.

PROJECT MANAGEMENT INSTITUTE (PMI). A Guide to the Project Management Body of Knowledge (PMBOK Guide) - Fifth Edition. Pennsylvania: PMI, 2013a.

. Standard for Portfolio Management - Third Edition. Estados Unidos da América: PMI Bookstore, 2013b.

SHAH, M.; NAQVI, I. H. Impact of Internal Stakeholder's Engagement on Project Portfolio Management Sucess, IT Industry in Lahore, Pakistan. Science International (Labore), Pakistan, Vol. 26, nro. 4, p. 1777-1782, 2014.

TAYLOR, J. Managing Information Technology Projects: Applying Project Management Strategies to Software, Hardware, and Integration Initiatives. New York: AMACOM, 2004.

TELlER, J.; KOCK, A.; GEMUNDEM, H. G. Risk Management in Project Portfolios is more than managing project risks: A Contingence Perspective on Risk Management. Estados Unidos: Project Management Journal, Vol. 45, Nro. 4, p. 67-80, 2014. 
Cláudio Luís Carvalho Larieira \& Alberto Luiz Albertin

WEILL, P.; OLSON, M. H. Managing investment in Information Technology: Mini case examples and implications. MIS Quarterly, Vol. 13, n 1, March 1989, p. 3-17.

YIN, R. K. Estudo de Caso - Planejamento e Métodos - 4a . edição. Porto Alegre: Bookman, 2010. 